\title{
Sequential R\&D and blocking patents in the dynamics of growth
}

\author{
Guido Cozzi · Silvia Galli
}

Published online: 25 December 2013

C) Springer Science+Business Media New York 2013

\begin{abstract}
The incentives to conduct basic or applied research play a central role for economic growth. How does increasing early innovation appropriability affect basic research, applied research, innovation and growth? In a common law system an explicitly dynamic macroeconomic analysis is appropriate. This paper analyzes the macroeconomic effects of patent protection by incorporating a two-stage cumulative innovation structure into a qualityladder growth model with endogenous skill acquisition. We focus on two issues: (a) the overprotection versus the under-protection of intellectual property rights in basic research; (b) the evolution of jurisprudence shaping the bargaining power of the upstream innovators. We show that the dynamic general equilibrium interactions may seriously mislead the empirical assessment of the growth effects of IPR policy: stronger protection of upstream innovation always looks bad in the short- and possibly medium-run. We also provide a simple "rule of thumb" indicator of the basic researcher bargaining power.
\end{abstract}

Keywords Endogenous growth · Basic and applied research · Endogenous technological change $\cdot$ Common law

JEL Classification $\mathrm{O} 31 \cdot \mathrm{O} 33 \cdot \mathrm{O} 34$

\section{Introduction}

Is an increase in the intellectual protection of basic research beneficial or harmful ${ }^{1}$ for innovation and growth? It is well known that the US economy in the 1980s witnessed a strengthen\footnotetext{
development, thus hampering downstream research for biomedical advance.

G. Cozzi $(\bowtie) \cdot$ S. Galli

Department of Economics, FGN-HSG, University of St. Gallen, Varnbüelstrasse 19, 9000 St. Gallen, Switzerland e-mail: guido.cozzi@unisg.ch

S. Galli

e-mail: silvia.galli@unisg.ch
}

${ }^{1}$ Heller and Eisenberg (1998) suggested the existence of a tragedy of the anticommons, i.e. a proliferation of upstream intellectual property rights which greatly amplify the transaction costs of downstream research and 
ing of intellectual property rights (IPR). Given the weaker initial protection of basic research results prevailing in the US until the early 1980s, this implied an increase in the relative bargaining power of the upstream innovators, and therefore a decrease in the relative bargaining power of the downstream innovators (i.e. applied researchers or developers).

This paper will show that an increase in the relative bargaining power of basic researchers has harmful short-run consequences for economic growth, even though it could be conducive to higher growth in the longer term. In fact, being basic and applied research endogenous, they respond to the underlying relative bargaining power of the upstream innovators in two opposite ways: $R \& D$ reallocates more upstream, thereby slowing down the pace of innovation for a while. As a consequence, econometric studies may end up wrongly detecting negative short-term effects of basic research on innovation and growth, with potentially misleading research policy implications. Therefore, by focussing on the composition effects of patent strength, we can explain the weak effects of stronger IPR on total R\&D and on growth, often found in the data. This analysis is related to the existing literature on basic research and economic growth, such as Gersbach et al. (2010, 2012), and Spinesi $(2007,2012)$, however here the focus is on the evolution of the private incentives for basic research by universities or other institutions. Unlike Aghion and Howitt (1996) and Chu et al. (2012), here basic research is not associated with horizontal innovation, but it co-exists with applied research in a quality ladder framework.

We will cast our analysis in a dynamic general equilibrium framework, to better capture all innovation-related features of the economy. We shall see how the normative assignment of relative bargaining power of basic versus applied researcher is also related to the returns to education. However, in our analysis, tracking the dynamics of the skill premium and endogenizing education is only instrumental to a better screening of the short- and longterm effects of basic research incentives on economic growth. A theory of functional income inequality should instead consider that $R \& D$ employment is only a fraction of the total employment of college workers, as in Galor and Moav (2000) model in which skills are endogenous, and the demand for schooling is increasing with ability-biased technological change; and as in Acemoglu (1998, 2002) and Kiley (1999), which show that education increases the market for the skill complementary inputs, thereby driving up the profitability of innovations that increase the productivity of the skilled and therefore the returns to higher education.

In the microstructure of our model, a two-stage cumulative innovation structure is developed: unlike Grossman and Shapiro (1987) and Green and Scotchmer (1995) we consider free entry by a multitude of firms. Differently from Bessen and Maskin (2009) analysis of sequential R\&D with complementary innovation, our approach features creative destruction. Unlike Chu's (2010a, 2010b) unambiguous effect of general IPR strengthening on inequality, we will show that tightening patent protection in basic research may increase or decrease wage inequality. Similarly to Furukawa (2007), increasing upstream patent rights has an inverted U-shaped effect on long-term growth, but due to restricted development rather than reduced experience.

In our framework, basic and applied research technologies are heterogenous and the bargaining power of the upstream innovation changes, ${ }^{2}$ thus stylizing the evolution of the US jurisprudence after 1980. From that date on, the US national system of innovation has been reshaped by a sequence of important new laws and by a cumulative sequence of sentences that set the precedents for future modifications in the jurisprudence. All these changes pointed

2 Our framework somewhat complements Eicher and García-Peñalosa (2008), that envisages endogenous IPR based on firm choice, instead of on jurisprudence evolution. 
to an increase in the appropriability of innovations at their initial stages. ${ }^{3}$ Being the US legal system a common-law regime, the jurisprudence evolved gradually ${ }^{4}$ in the direction of stricter intellectual protection of research tools, ${ }^{5}$ basic research ideas, ${ }^{6}$ etc. The essence of the common law is that it is made by judges sitting in courts, by applying their common sense and knowledge of legal precedent (stare decisis) to the facts before them. During the early 1980s began a progressive process in which the U.S. Court decisions changed from the old doctrine limiting the patentability of early-stage scientific discoveries to the conception that also fundamental basic scientific findings (such as genetic engineering procedures or semiconductor designs) are patentable. This process took a quarter century, culminating in the 2002 Madey vs. Duke University Federal Circuit's decision, which completed a process of elimination of the "research exemption" to patent claims. Interestingly, the more recent cases seem to be witnessing an opposite trend, most notably Merck vs. Integra Lifesciences (2005), in which the Supreme Court decided to re-affirm research exemption in the pharmaceutical sector.

If what deeply characterizes common law (and sharply separates it from the Continental Europe-type legal systems) is an uninterrupted continuity such that within the stare decisis regime an institutional break point is even hardly conceivable, we must conclude that the analysis of the effects of the US patent policy on the economy is forced to include the whole transition dynamics. The law and economics literature is currently modelling the evolution of the case law in the perspective of analyzing Benjamin Cardozo's and Richard Posner's view of common law as efficiency promoting. In fact, according to this influential view, unlike civil law, being the common law decentralized, it follows the aggregate decision making of several heterogenous judges, whose idiosyncratic opinions average one another. Moreover, the very sequential precedent structure, implies that one appellate court overrules another's decision, tending to progressive mitigation and efficiency only if the majority of the judges is unbiased, depending also on the judge's effort cost of changing the legal rule established in a precedent (Gennaioli and Shleifer 2007b). Appellate courts may change a previously established legal rule also by "distinguishing" the case based on the consideration of a "previously neglected dimension" (Gennaioli and Shleifer 2007a), which can facilitate convergence towards a more efficient legal rule. We wonder whether the increasingly pro-upstream $R \& D$ court orientation from the early 1980s to 2002 has benefited innovation or just followed the bias of less and less liberal judges.

In this paper, we also look for potentially detectable aspects of the time series of several important variables-skill wage premium, education, innovation, labour force allocation, and the market value of patents-associated with either long-term evolution of the legal rules. In doing so, we follow a dynamic general equilibrium perspective, which allows us to

\footnotetext{
3 Including the Stevenson-Wydler act of 1980 and the Bayh-Dole act, of 1980, which amended the patent law to facilitate the commercialization of inventions obtained thanks to government funding, especially by universities. The pro-early innovation cultural change is also reflected in the increasing protection of tradesecrets-starting in the 80 s with the Uniform Trade Secret Act and culminating with the Economic Espionage Act of 1996 (Cozzi 2001) — as well as in the increasingly positive attitude towards software patents (Hunt 2001; Hall 2009), culminating in the Final Computer Related Examination Guidelines issued by the USPTO in 1996.

4 In our case, it is important to recall Janice Mueller's (2004) account of the common law development of a narrow experimental use exemption from patent infringement liability: with special reference to the discussion of the change in the doctrine from 1976s Pitcairn v. United States, through 1984s Federal Circuit decision of Roche Products, Inc. v. Bolar Pharmaceutical Co., all the way to Madey v. Duke University in 2002.

5 Another important source of change in sharpening IPRs can be driven by special interests, as studied by Chu (2008).

6 See Gallini (2002), Mueller (2001, 2004), and Scotchmer (2004).
} 
assume that economic agents are sufficiently intelligent to detect what "trend" is occurring, and suitably take optimizing decisions.

In order to analyze the effects of an expected and progressive change in the patent protection of basic research, we therefore need to simulate all variables in their transitional dynamics. We will extract lessons from our numerical results, useful to detect whether increasing basic research protection common law doctrine is gradually facilitating the national system of innovation or evolving for the worse.

The remainder of this paper is organized as follows. Sections 2 and 3 set up the model for the case of exogenous skill composition, which is useful to introduce the main aspects of our model and to draw some preliminary predictions. Section 4 characterizes the equilibrium and the steady state, and shows some representative simulations of the transition of our economy driven by a change in the upstream researcher's bargaining power. Section 5 extends the model to endogenous skill acquisition, and Sect. 6 characterizes the equilibrium and the steady state of this full model. Section 7 analyzes a special case, useful as a benchmark and derives a potentially useful empirical "rule of thumb". Section 8 identifies a potentially important problem with blocking patents. In Sect. 9 we show the numerical simulations of the transitional dynamics of the full model, and test their robustness to some extensions. Section 10 concludes. The most challenging proofs are in Appendix.

\section{The model}

\subsection{Households}

In this section, we introduce a simple version of our model, leaving the labour-force skill composition exogenous. This will allow the reader to understand the logic of our main results in a relatively simple way, while preparing the stage for the full model, with endogenous skill acquisition, which will be carried out in Sect. 5. We assume an economy in which the individual decisions are taken within the household by maximizing the following intertemporally additive utility functional:

$$
U=\int_{0}^{\infty} e^{-\rho t} u(t) d t
$$

where $\rho>0$ is the subjective rate of time preference and $u(t)$ is the per-family member instantaneous utility. In turn, $u(t)$ is defined as:

$$
u(t)=\int_{0}^{1} \ln \left[\sum_{j} \gamma^{j} d_{j t}(\omega)\right] d \omega,
$$

where $d_{j t}(\omega)$ is the individual consumption of a good of quality $j=1,2, \ldots$ and produced in industry $\omega \in[0,1]$ at time $t$, and bought at price $p_{j t}(\omega)$. Parameter $\gamma>1$ measures the size of the quality upgrades. In each household a fraction $h$ of the labour endowment is skilled, ${ }^{7}$ earning wage $w_{H}$, and a fraction $l=1-h$ is unskilled, earning wage $w_{L}$, which we will normalize to 1 . Skilled labour can work both in manufacturing and R\&D, whereas unskilled labour can only work in manufacturing.

\footnotetext{
7 We will endogenize skill acquisition in Sect. 5.
} 
Defining per-capita expenditure on consumption goods as $e(t)=\int_{0}^{1}\left[\sum_{j} p_{j t}\right.$ $\left.(\omega) d_{j t}(\omega)\right] d \omega$, the real interest rate as $i(t)$, time 0 intertemporal budget constraint is $\int_{0}^{\infty} e^{g t-\int_{0}^{t} i(\tau) d \tau} e(t) d t \leq F(0)$, where $F(0)$ is the present discounted value of all future family incomes, i.e. wages, interests, and dividends. Let percapita asset holdings at time $t$ be denoted by $a(t)$.

Following standard steps of quality ladder theory, ${ }^{8}$ we can show that the consumers will only buy goods with the lowest quality-adjusted price, and that the Euler equation applies:

$$
\dot{e}(t) / e(t)=i(t)-(\rho+g)=r(t)-\rho,
$$

where $r(t) \equiv i(t)-g$ is the population growth deflated instantaneous interest rate at time $t$. Equation (3), initial percapital assets, $a(0)$, together with the transversality condition

$$
\lim _{t \rightarrow \infty} a(t) \int_{0}^{\infty} e^{-\int_{0}^{t} r(\tau) d \tau}=0,
$$

determines the consumer choice of $e(t)$.

\subsection{Manufacturing}

In each final good industry $\omega \in[0,1]$ and for each quality level $j(\omega)$ of the good, production is carried out according to the following Cobb-Douglas production function

$$
Y(\omega, t)=X^{\alpha}(\omega, t) L^{1-\alpha}(\omega, t), \text { for all } \omega \in[0,1],
$$

where $\alpha \in(0,1), Y(\omega, t)$ is the output flow at time $t, X(\omega, t)$ and $L(\omega, t)$ are the skilled and unskilled labour inputs. In each industry firms minimize costs by choosing input ratios

$$
\frac{X(\omega, t)}{L(\omega, t)}=\frac{1}{w_{H}(t)} \frac{\alpha}{1-\alpha} .
$$

The total per-capita amount $l(t)$ of unskilled labour only works in the manufacturing sectors. Therefore the aggregate skilled labour demand is equal to:

$$
X(\omega, t)=\frac{1}{w_{H}(t)}\left(\frac{\alpha}{1-\alpha}\right) l(t) N(t)
$$

In per-capita terms,

$$
x(\omega, t) \equiv \frac{X(\omega, t)}{N(t)}=\frac{1}{w_{H}(t)}\left(\frac{\alpha}{1-\alpha}\right) l(t) \equiv x(t) .
$$

Moreover, percapita output is:

$$
y(\omega, t) \equiv \frac{Y(\omega, t)}{N(t)}=\frac{1}{w_{H}(t)^{\alpha}}\left(\frac{\alpha}{1-\alpha}\right)^{\alpha} l(t) \equiv y(t) .
$$

As in Aghion and Howitt (1992), skilled labour can also work in the R\&D sectors. Therefore, a higher skill premium $w_{H}(t)$ frees resources for the R\&D sectors.

We assume instantaneous Bertrand competition in all sectors. Due to Cobb-Douglas preferences, consumers allocate the same budget to each variety, regardless of its quality. Since

8 See Segerstrom et al. (1990), Grossman and Helpman (1991a) and Segerstrom (1998). 
only the owner of the most recent top quality good patent can produce the top quality version of its sector good, the equilibrium price ${ }^{9}$ will be equal to a mark-up $\gamma>1$ over the unit cost $c\left(w_{H}(t), 1\right)$. Since price is equal to $p_{j t}(\omega)=\gamma c\left(w_{H}(t), 1\right)$, in any equilibrium per-capita demand is $d_{j t}(\omega)=\frac{e(t)}{\gamma c\left(w_{H}(t), 1\right)} \equiv d(t)$, which is symmetric. Therefore, in each sector $\omega \in[0,1]$, the temporary monopolist who owns the top quality product patent earns the same profit $\Pi(\omega, t)=\Pi(t)$, which, in per-capita terms, is equal to ${ }^{10}$ :

$$
\begin{aligned}
\frac{\Pi(t)}{N(t)} & \equiv \pi(t)=\frac{\gamma-1}{\gamma} e(t)=(\gamma-1) \frac{w_{H}(t) x(t)}{\alpha} \\
& =(\gamma-1) \frac{1}{1-\alpha} l(t),
\end{aligned}
$$

where in equilibrium $l(t)=l$ constant.

Similarly for the skilled labour market equilibrium condition

$$
x(t)+m\left(A_{0}(t)\right) n_{B}(t)+\left(1-m\left(A_{0}(t)\right)\right) n_{A}(t)=h(t),
$$

where $h(t) \equiv H(t) / N(t)=h$ is the (constant in equilibrium) aggregate population-adjusted human capital, $m\left(A_{0}(t)\right)$ denotes the mass of sectors where basic research is undertaken at time $t$, and $1-m\left(A_{0}(t)\right)$ denotes mass of sectors where basic research is not undertaken.

\section{R\&D and Schumpeterian dynamics}

The quality level $j$ of each final product of variety $\omega \in[0,1]$ can increase as a result of $R \& D$ undertaken by private firms. In order to capture the interaction between basic and applied research, we assume that a basic research idea is a pre-requisite to applied research and applied R\&D success opens the door for a further basic research advance. The first stage- basic research-is the outcome of a Poisson process with probability intensity $\frac{\lambda_{0}}{N(t)}\left(\frac{N_{B}(\omega, t)}{N(t)}\right)^{-a}$ per unit of research labour, where $\lambda_{0}>0$ is a basic research productivity parameter, $N_{B}(\omega, t)$ is the mass of research labour employed in sector $\omega$ at time $t$, and $a>0$ is a congestion externality parameter.

The second stage - applied research—completes the basic research idea and generates the new higher quality good according to a Poisson process with probability intensity $\frac{\lambda_{1}}{N(t)}\left(\frac{N_{A}(\omega, t)}{N(t)}\right)^{-a}$ per unit of research labour, where $\lambda_{1}>0$ is an applied research productivity parameter; $N_{A}(\omega, t)$ is the mass of research labour employed in sector $\omega$ at time $t$; and $a>0$ is the congestions externality parameter. The presence of population size, $N(t)$, in the denominator states that $R \& D$ difficulty increases with the total population in the economy, ${ }^{11}$ which delivers endogenous growth without the strong scale effect, ${ }^{12}$ as suggested by Smulders and van de Klundert (1995), Young (1998), Peretto (1998, 1999), Dinopoulos

9 As in Grossman and Helpman (1991b, pp. 88-91).

10 The second equality builds on the Cobb-Douglas property that minimum total cost is $\left[\left(\frac{1-\alpha}{\alpha}\right)^{-(1-\alpha)}+\left(\frac{\alpha}{1-\alpha}\right)^{-\alpha}\right] w_{s}(t)^{\alpha} w_{u}(t)^{1-\alpha} X(\omega, t)^{\alpha} L(\omega, t)^{1-\alpha}$. Notice that profit is $(\gamma-1)$ times total costs because unit costs are constant due to the assumed constant returns to scale (CRS) technology. Using Eq. (8) and simplifying gives the result.

11 Population density favours innovation at the local level (see Carlino and Hunt 2001): according to this solution to the strong scale effect, the dilution of R\&D is not related to population density, but with the overall size of the economy.

12 See Dinopoulos and Thompson (1999) and Jones (2005). 
and Thompson (1998), Howitt (1999), and recently confirmed empirically by Ha and Howitt (2007) and Madsen (2008).

Defining $n_{B}(\omega, t) \equiv \frac{N_{B}(\omega, t)}{N(t)}$ and $n_{A}(\omega, t) \equiv \frac{N_{A}(\omega, t)}{N(t)}$, as the skilled labor employment in each basic and, respectively, applied R\&D sector, we can express the expected innovation rate in a $\omega^{\prime}$ sector undertaking only basic $\mathrm{R} \& \mathrm{D}$ as $\lambda_{0} n_{B}\left(\omega^{\prime}, t\right)^{1-a}$ and the expected innovation rate in a $\omega^{\prime \prime}$ sector undertaking only applied $\mathrm{R} \& \mathrm{D}$ as $\lambda_{1} n_{A}\left(\omega^{\prime \prime}, t\right)^{1-a}$. All stochastic processes are independent both across sectors and across firms. Hence, the existence of a continuum of sectors implies that the law of large number applies and aggregate variables evolve deterministically. Since all sectors switch from hosting only basic R\&D firms-belonging to subset $A_{0}(t) \subset[0,1]$ - to hosting only applied R\&D-belonging to subset $A_{1}(t) \subset[0,1]$ 一 the mass of sectors belonging to each type will flow deterministically. ${ }^{13}$ Notice that $A_{0}(t) \cup A_{1}(t)=[0,1]$ and $A_{0}(t) \cap A_{1}(t)=\emptyset$. Moreover, in our model, symmetric equilibria exist, allowing us to simplify notation: $n_{B}(\omega, t) \equiv n_{B}(t)$ and $n_{A}(\omega, t) \equiv n_{A}(t)$. Therefore, if $\left.m\left(A_{0}(t)\right) \in\right] 0,1\left[\right.$ is the Lebesgue mass of the $A_{0}(t)$ subsetand hence $m\left(A_{1}(t)\right)=1-m\left(A_{0}(t)\right)$ the Lebesgue mass of $A_{1}(t)$ subset-its evolution will be deterministic and described by the following first order differential equation:

$$
\frac{d m\left(A_{0}(t)\right)}{d t}=\left(1-m\left(A_{0}(t)\right)\right) \lambda_{1}\left(n_{A}(t)\right)^{1-a}-m\left(A_{0}(t)\right) \lambda_{0}\left(n_{B}(t)\right)^{1-a} .
$$

We assume free entry into basic and applied research. Each inventor, be she basic or applied, is granted a patent. However, though the first R\&D firm that invents a new final product gets the patent anyway, it will infringe the patent held by the previous basic research inventor. Therefore it will have to bargain with the basic research patent holder in order to produce the new version of this good. A patent gives its holder a "right to block", but he/she will exercise it only to the extent that it is profitable to do so: this confers him/her the ability to obtain a share of the final good patent value, because it allows him/her to credibly threaten to block the production of the newly discovered final good in case negotiations fail. This "right to block" is essential because otherwise the successful applied researcher would just walk away with the full value of the final good patent, leaving basic research unrewarded. ${ }^{14}$

Such a framework captures important aspects of the real world disputes between inventors whose patent claims allow the blocking of inventions. ${ }^{15}$ Let $\left.\beta(t) \in\right] 0,1[$ denote the share of the final product (applied) patent value assigned - at the end of the negotiations taking place at time $t$ - to the upstream (basic) patent holder. ${ }^{16}$ This share captures time $t$ court orientation towards intellectual property. Changes in the jurisprudence towards stronger patent claims and weaker research exemptions would correspond to increases in $\beta(t)$, whereas a gradually looser upstream patent holder protection and stronger research exemptions would correspond to a declining $\beta(t)$. Taken literally, $\beta(t)$ can be obtained as a Nash bargaining solution between the patent blocker and the applied developer, with the courts orientation dictating the relative bargaining power. Theoretically, it is important to notice that both patent holders' outside

\footnotetext{
13 Provided the initial Lebesgue mass of each was positive.

14 For basic research in the presence of non-pecuniary rewards, see Cozzi and Galli (2009).

15 O'Donoghue and Zweimüller (2004) and Chu (2009) are indirectly related, as they capture the role of patent claims in molding the bargaining between current and future innovators: their concepts of patentability requirement and leading breadth could be re-adapted here to accomodate the blocking power of the upstream patent holder.

16 Assuming that basic and applied innovators match and target applied innovator-specific innovations, we could re-read this strategic interaction as Aghion and Tirole's (1994a, 1994b) research unit (RU) and customer (C). Then our case would clearly correspond to when RU's effort is important $\left(\tilde{U}_{C}>U_{C}\right)$, which implies that "the property right is allocated to RU" (Aghion and Tirole 1994b, p. 1191). In this light, our $\beta(t)$ generalizes Aghion and Tirole's (1994a, 1994b) equal split assumption.
} 
options are zero: in case bargaining breaks down the applied patent holder cannot produce (zero profit), while the patent blocker cannot complete or find another completer because the application is now prior art. ${ }^{17}$

In what follows, we will consider gradual changes in patent policy in terms of the sign of $\dot{\beta}(t)$. We will assume that the following specification holds:

$$
\dot{\beta}(t)=(1-\psi)(\bar{\beta}-\beta(t)) .
$$

Equation (13) is a linear differential equation with constant coefficients, which describes the speed of change in $\beta(t)$ per unit time. Parameter $\psi<1$ guarantees asymptotic stability and $\bar{\beta} \in] 0,1[$ is the steady state. We will consider the progressive tightening of intellectual property rights in the US as the result of a sudden change in $\bar{\beta}$, which determines a gradual increase in $\beta(t)$ from its previous lower steady state level to its new level.

It is important to notice that we are in a rational expectations framework: in our model, all economic agents can predict, after the regime change, the successive increases in $\beta(t)$, and all decisions are re-optimized accordingly. Hence all our numerical simulations are immune to Lucas' critique. In fact, the steady upstream shift of innovation incentives is too regular not to be incorporated in people's expectations, which leads law scholars to view post-1980 as a sort of structural break of Eq. (13), and forces us to study the whole transitional dynamics of the model's economy. The statutory decisions taken in the early 1980s triggered a gradual change in the common law. ${ }^{18}$

Let us define $v_{B}, v_{L}^{0}$, and $v_{L}^{1}$ as the population-adjusted present expected value of a basic research patent $\left(v_{B}\right)$, of an $A_{0}$ industry quality leader $\left(v_{L}^{0}\right)$, and of an $A_{1}$ industry challenged leader $\left(v_{L}^{1}\right)$.

Costless arbitrage between risk free activities and firms' equities imply that in equilibrium at each instant the following equations shall hold:

$$
\begin{aligned}
w_{H}(t) & =\lambda_{0} n_{B}(t)^{-a} v_{B}(t) \\
r(t) v_{B}(t) & =\lambda_{1} n_{A}(t)^{1-a}\left(\beta(t) v_{L}^{0}(t)-v_{B}(t)\right)+\frac{d v_{B}(t)}{d t} \\
w_{H}(t) & =\lambda_{1} n_{A}(t)^{-a}(1-\beta(t)) v_{L}^{0}(t) \\
r(t) v_{L}^{0}(t) & =\pi(t)-\lambda_{0} n_{B}(t)^{1-a}\left(v_{L}^{0}(t)-v_{L}^{1}(t)\right)+\frac{d v_{L}^{0}(t)}{d t} \\
r(t) v_{L}^{1}(t) & =\pi(t)-\lambda_{1} n_{A}(t)^{1-a} v_{L}^{1}(t)+\frac{d v_{L}^{1}(t)}{d t}
\end{aligned}
$$

The value of a monopolist in an $A_{0}$ industry, $v_{L}^{0}$, has to obey Eq. (14d): in fact, the shareholders of the current quality leader compare the risk free income, $r v_{L}^{0}$, obtainable from selling their shares and buying risk free bonds to the expected value of their profits, $\pi$, net of probable capital loss, $\lambda_{0} n_{B}^{1-a}\left(v_{L}^{0}-v_{L}^{1}\right)$, in case a new basic research result appears in the industry.

As soon as a new basic R\&D result appears in the industry, the incumbent monopolist's value falls down to a lower, but still positive, value $v_{L}^{1}$, which has to obey Eq. (14e): as before, risk free income is equated to expected profits net of expected capital loss, but now the probability of the basic research idea's being completed by applied research in the industry,

\footnotetext{
17 In the more realistic case that basic research results have multiple applications, this would increase the blocker's outside option and its equilibrium share of the final patent value.

18 According to Fon and Parisi (2006), such a case evolution could also appear in a civil law system.
} 
$\lambda_{1} n_{A}^{1-a}$, is the monopolistic profit hazard rate, as the arrival of the new final product implies the complete displacement of the current leading edge product.

Equation (14a) characterizes free entry into basic R\&D (in an $A_{0}$ industry), equalizing the skilled wage to the probability $\lambda_{0} n_{B}^{-a}$ of inventing times the value $v_{B}$ of the resulting patent.

Equation (14b) equates the risk free income from selling a basic R\&D patent, $r v_{B}$, to the expected earnings from holding it in an $A_{1}$ industry — given by the expected capital gain, $v_{L}^{0}-v_{B}$, generated by the $n_{A}$ downstream researchers' discovering the industrial application, plus the gradual appreciation in the case of applied R\&D not succeeding, $\frac{d v_{B}}{d t}$.

Equation (14c) is the free entry condition for applied researchers who rationally expect to appropriate only fraction $1-\beta$ of the value of the final good monopolist.

It is interesting to remark that we are not restricting the basic research patent holder from undertaking applied R\&D on its own research tool and developing its final good patent "inhouse". We are just allowing other applied researchers to develop that idea equally well. In fact, were the basic patent holder hiring $n_{b}>0$ units of human capital, ${ }^{19}$ we would rewrite Eq. (14b) as:

$$
\begin{aligned}
r(t) v_{B}(t)= & \lambda_{1} n_{A}(t)^{1-a}\left(\beta(t) v_{L}^{0}(t)-v_{B}(t)\right)-n_{b} w_{H}(t) \\
& +n_{b} \lambda_{1} n_{A}(t)^{-a}(1-\beta(t)) v_{L}^{0}(t)+\frac{d v_{B}(t)}{d t} \\
= & \lambda_{1} n_{A}(t)^{1-a}\left(\beta(t) v_{L}^{0}(t)-v_{B}(t)\right)+\frac{d v_{B}(t)}{d t},
\end{aligned}
$$

where the second equality follows from Eq. (14c). Hence our Eq. (14b) entails no loss of generality, and it is consistent with private basic research done within large companies which utilize their innovations themselves: all we need for our equations to be valid and for the aggregate predictions we obtain is to assume free entry into both basic and applied research. ${ }^{20}$

It is useful to remark that free entry into both basic and applied research guarantees zero average profits. For this reason, our model is not only suitable for the analysis of private $\mathrm{R} \& \mathrm{D}$, but also for characterizing basic research undertaken by institutions (universities and non-profit institutions, federal laboratories, foundations) which do not look for profits, but may be constrained to break even.

\section{Equilibrium}

In equilibrium, households choose consumption to maximize utility taking prices as given, manufacturing firms compete in each industry choosing their prices; basic research firms, applied research firms, and basic research patent holders maximize their profits taking prices as given; all markets clear; all arbitrage opportunities have been exploited; the stock variable, $m\left(A_{0}(t)\right)$, evolves according to its law of motion. More specifically, we focus on a symmetric equilibrium, which implies that all industry variables are equal: it consists in a time path of quantities $\beta(t), x(t), y(t), n_{B}(t), n_{A}(t)$, and $m\left(A_{0}(t)\right)$, a time path of prices $r(t), v_{B}(t)$,

\footnotetext{
19 Notice that $n_{b}$ does not affect the aggregate innovation rate $n_{A}$ in the industry, which is determined by the free-entry condition (14c). Moreover $n_{b}>n_{A}$ would not be individually rational, generating negative expected profits. Hence in equilibrium the basic research patent holder will invest up to $n_{b} \leq n_{A}$ and free entrant applied researchers will invest the remaining $n_{A}-n_{b}$.

20 See Cozzi (2007) for further discussion on the role of free entry into applied research.
} 
$v_{L}^{0}(t), v_{L}^{1}(t), w_{H}(t), \pi(t)$, such that at each instant of time $t \geq 0$, Eqs. (3), (4), (8), (11), (9), (12), (13), (14a), (14b), (14c), (14d), and (14e) are satisfied.

In a steady state, the time derivatives of the percapita variables of the above-mentioned equations are constant, and we can state:

Definition A steady state equilibrium is a vector $\left[\beta, x, y, n_{B}, n_{A}, m\left(A_{0}\right), r, v_{B}, v_{L}^{0}, v_{L}^{1}\right.$, $\left.w_{H}, \pi\right] \in R_{++}^{12}$ which satisfies the following equations:

$$
\begin{aligned}
& \beta=\bar{\beta} \\
& r=\rho \\
& x=\frac{1}{w_{H}}\left(\frac{\alpha}{1-\alpha}\right) l \\
& y=\frac{1}{w_{H}^{\alpha}}\left(\frac{\alpha}{1-\alpha}\right)^{\alpha} l \\
& \pi=(\gamma-1) \frac{1}{1-\alpha} l \\
& x+m\left(A_{0}\right) n_{B}+\left(1-m\left(A_{0}\right)\right) n_{A}=h \\
& \left(1-m\left(A_{0}\right)\right) \lambda_{1}\left(n_{A}\right)^{1-a}=m\left(A_{0}\right) \lambda_{0}\left(n_{B}\right)^{1-a} \\
& \quad w_{H}=\lambda_{0} n_{B}^{-a} v_{B} \\
& \quad r v_{B}=\lambda_{1} n_{A}^{1-a}\left(\beta v_{L}^{0}-v_{B}\right) \\
& w_{H}=\lambda_{1} n_{A}^{-a}(1-\beta) v_{L}^{0} \\
& \quad r v_{L}^{0}=\pi-\lambda_{0} n_{B}^{1-a}\left(v_{L}^{0}-v_{L}^{1}\right) \\
& \quad r v_{L}^{1}=\pi-\lambda_{1} n_{A}^{1-a} v_{L}^{1} .
\end{aligned}
$$

In the steady state, the aggregate innovation rate is given by the total number of applied R\&D blueprints created per unit time, because it is not until the applied research succeeds that welfare increases. The aggregate probability of applied R\&D success is given by $\left(1-m\left(A_{0}\right)\right) \lambda_{1}\left(n_{A}\right)^{1-a}$. Notice that in a steady state this is also equal to the total number of basic research results created per unit time, i.e. $m\left(A_{0}\right) \lambda_{0}\left(n_{B}\right)^{1-a}$, as shown in Eq. (21). It is easily proved that the number of quality jumps per unit time is proportional (by factor $\log \lambda$ ) to the growth rate of the representative agent's instantaneous utility.

\subsection{Dynamic effects of upstream patents}

In this section we will illustrate the main effects of an increase in the bargaining power of the upstream innovator, i.e. of the basic researchers, on innovation and on the skill premium, which follow from our model's dynamics. We have undertaken several numerical simulations and detected common patterns. We provide here two numerical simulations highly representative of the several simulations we have undertaken. Figure 1 shows the effects of a gradual change of $\beta$ from 0.35 to 0.50 , fully expected by the individuals, leading from an initial steady state characterized by $\bar{\beta}=0.35$ to a final steady state associated with $\bar{\beta}=0.50$.

As the reader can see, the increase in $\beta$ leads to an increase in the value of the basic research patent, because it gives it more rights on the final good patent. This incentivizes basic research, both at the aggregate (third plot) and at the industry (eighth plot) level. Symmetrically, the increase in $\beta$ disincentivizes applied $R \& D$, both at the aggregate (fourth plot) and at the industry level (ninth plot). Notice how applied R\&D seems to recover a bit 

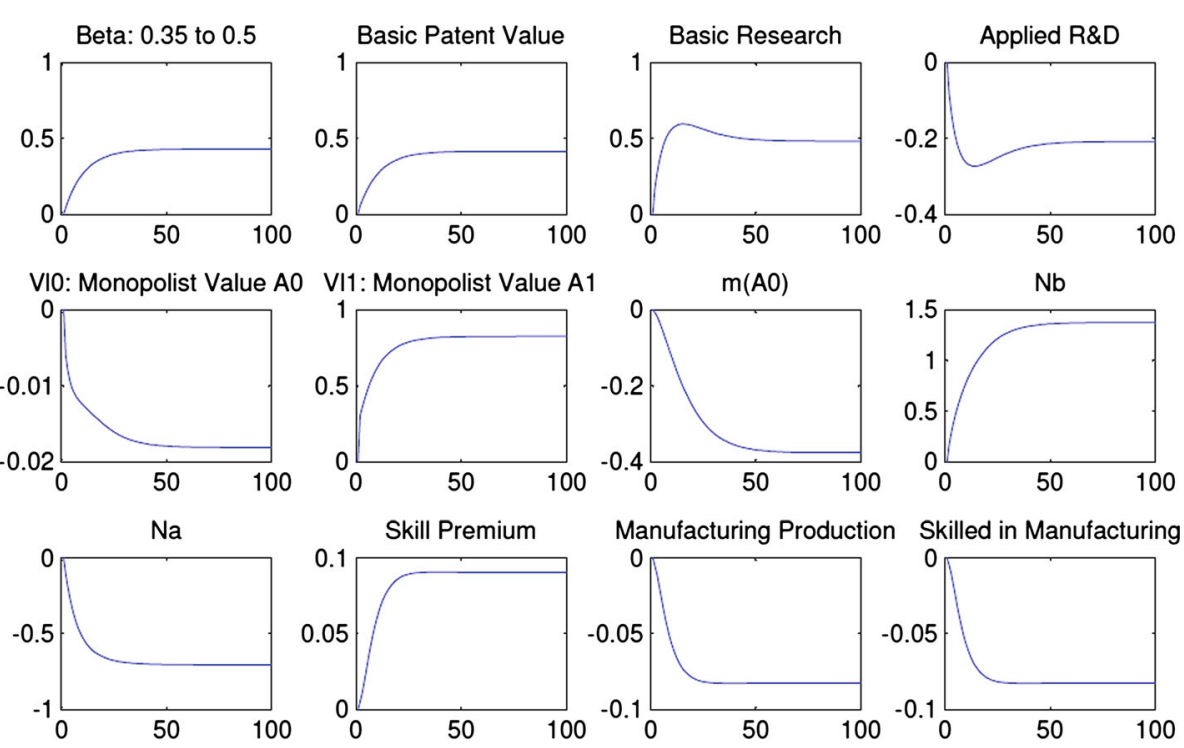

Aggregate Innovation Rate

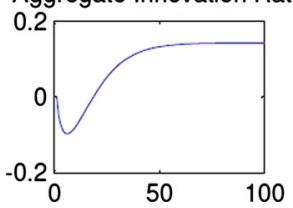

Fig. 1 Growth enhancing transition

after a while: this is a consequence of the increase in the number of research tools made available following the increase in basic research. In fact, we can see (in the seventh plot of the figure) that $m\left(A_{0}\right)$ is declining, as a consequence of more basic research and less applied R\&D per-sector. This implies that $1-m\left(A_{0}\right)$ increases: more avenues open up for applied $\mathrm{R} \& \mathrm{D}$ itself. This overshooting dynamics of applied $\mathrm{R} \& \mathrm{D}$ over time is a very robust finding of our simulations, as is that of basic research (third panel): the gradual decline in $m\left(A_{0}\right)$ partially compensates the increase in basic research, now squeezed in a smaller number of sectors.

The decrease in $v_{L}^{0}$ and the increase in $v_{L}^{1}$ reflect the increase in the (partial) obsolescence of the monopolist in $A_{0}$ and the decrease in the obsolescence of the monopolist in $A_{1}$. Important, and very robust as well, are the trajectories depicted in the 10th, 11th, and 12th plots: the increase in basic $R \& D$ outweighs the decrease in applied $R \& D$, which implies an increase in skilled labour demand for R\&D purposes; this raises the skill premium, which liberate human capital from manufacturing. Declining skilled employment in manufacturing in turn reduces manufacturing production. The consequence on the aggregate innovation rate is positive, due to a better realignment of basic and applied research along with an increase in the mass of skilled labour allocated to innovation.

Finally, all this is reflected by the last plot, which presents a pattern which we have found in all simulations we have carried out: as a consequence of higher values of $\beta$ the initial response of the aggregate innovation rate is negative. The reason is that the stock of research tools available moves gradually, being $m\left(A_{1}\right)$ a predetermined variable of our model. Therefore, as the applied $\mathrm{R} \& \mathrm{D}$ per-sector, $n_{A}$, declines the available research tools line will be completed 

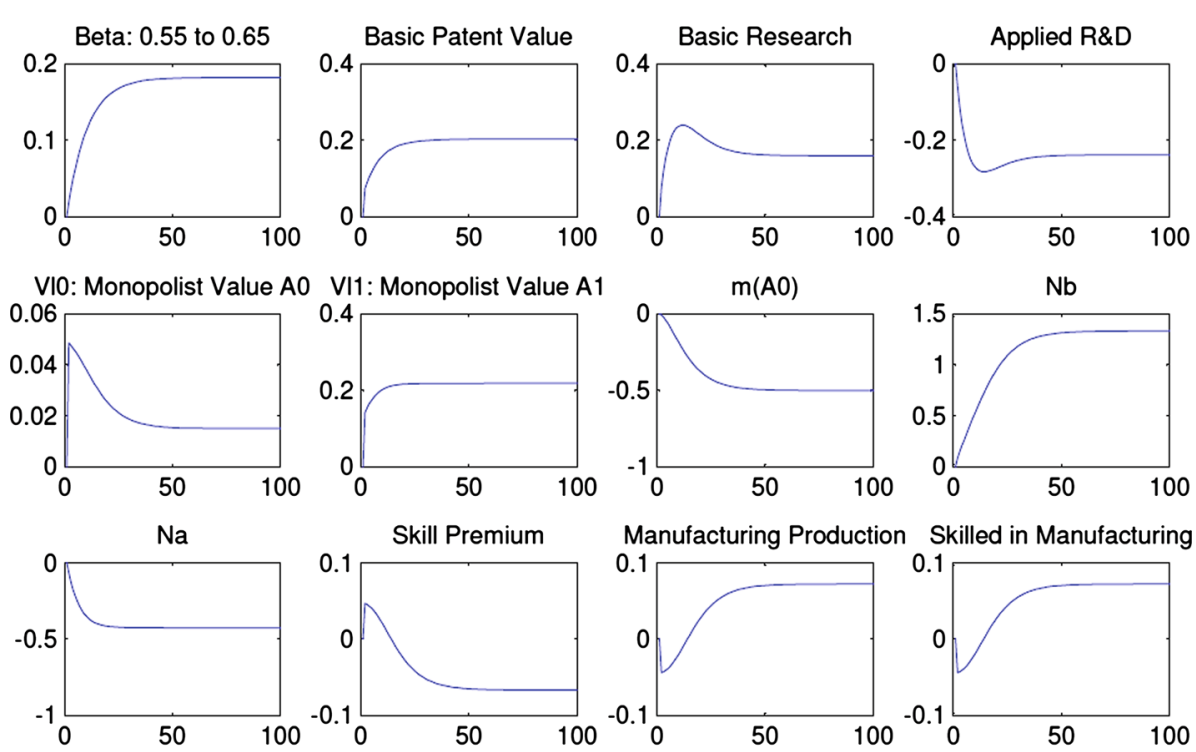

Aggregate Innovation Rate

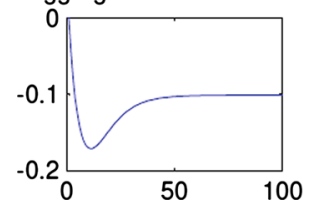

Fig. 2 Growth harming transition

more slowly, with resulting drop in the aggregate final good patenting activity. As the more intense flow of new research tools cumulates over time, the stock of research tools will facilitate applied $R \& D$ and eventually raise the aggregate innovation rate.

While in Fig. 1 parameters were such that the increase in $\beta$ was eventually beneficial for aggregate innovation, we report in Fig. 2 what happens when the increase in $\beta$ is detrimental to growth, that is when the basic research patent holder has too high a bargaining power. In Fig. 2 we show the effects of a gradual change of $\beta$ from 0.55 to 0.65 :

In both figures the dynamics of basic and applied R\&D, both at the sectoral and at the aggregate level, are similar, as is the dynamics of the monopolists and of the basic patent holder. However, what differs this time is that the increase in $\beta$ is too high, discouraging applied R\&D more than it encourages basic $R \& D$, and leading to a too imbalanced allocation of human capital. As a result, the initially high level of $m\left(A_{0}\right)$ attracts a lot of basic R\&D - that is $n_{B} m\left(A_{0}\right)$ rises - sufficient to increase the demand for human capital in $\mathrm{R} \& \mathrm{D}$, to increase the skill premium, and to decrease manufacturing production, as in Fig. 1. However, as soon as the flow out of $A_{0}$ cumulates, the increase in $m\left(A_{1}\right)=1-m\left(A_{0}\right)$ induces a massive lay off of basic researchers, with consequence drop in the demand for human capital and in the skill premium, with consequence increase in the manufacturing employment and output. As for aggregate innovation, in this case the many research tools available are developed by a more scanty applied $R \& D$, with insufficient completion rates and, therefore, smaller aggregate flow of better final products. Interestingly - and robustly - the aggregate innovation rate first fall and then partially recovers, reminiscent of Fig. 1, but not enough to compensate the initial drop. 
In both figures, the increase or decrease in the skill premium does not affect the overall stock of human capital, while instead it would be more realistic to assume that schooling (college in particular) decisions are responsive to the skill premium. In the next sections, we will in fact extend our model to the endogenous acquisition of skill through education. However, the results obtained to far will prove quite robust also in the richer framework.

\section{Endogenous skill acquisition}

In this section, we extend the model of the previous section to allow for the skill premium to incentivize education and the acquisition of skill. This renders human capital and unskilled labour endogenous. Importantly, such an extension allows us to study the consequences of research policy and jurisprudence evolution on schooling decisions and human capital formation.

Let us assume, as before, a large number of dynastic families-normalized to 1 at date $t=0$. However, we will assume that the household members are born at birth rate $b$ and pass away at rate $\delta$, living a period of duration $D$. The resulting population growth rate $^{21}$ is $g=b-\delta>0$. This demographic structure implies the following restrictions: $b=\frac{g e^{g D}}{e^{g D}-1}$ and $\delta=\frac{g}{e^{g D}-1}$. At time $t$ the total number of individuals is $N(t)=e^{g t}$. Each individual can spend her life working as unskilled or studying the first $T_{r}<D$ periods and then working as skilled. Each individual cares only about the utility of the average family member. Hence, despite bounded individual life, the individual decisions are taken within the household by maximizing the same intertemporally additive utility functional as in the the previous economy (with exogenous skill composition):

$$
U=\int_{0}^{\infty} e^{-\rho t} u(t) d t,
$$

where $\rho>0$ is the subjective rate of time preference, and $u(t)$ obeys Eq. (2). Following the same steps as before, also the Euler equation (3) and the transversality condition (4) continue to hold.

Individuals differ in their learning ability $\theta$, which, for each generation, is uniformly distributed over the unit interval. Following Dinopoulos and Segerstrom (1999), we assume that there is a minimum level of ability $\Gamma \in[0,1)$ below which individuals obtain nonpositive human capital from schooling. More specifically, an individual of ability $\theta \in[0,1]$ will be able to acquire $\theta-\Gamma$ units of human capital after an indivisible training period of length $T_{r}$. This guarantees that a fraction of the population larger than $\Gamma$ will never choose to get skilled. The only cost of education is the individual's time, which prevents her from earning the unskilled wage $w_{u}$. In what follows we choose unskilled labour as our numeraire, and therefore set $w_{u}(t)=1$ at all $t \geq 0$.

Hence an individual born at $t$, with (known) ability $\theta(t) \in[0,1]$ and who decides to educate herself will earn nothing from $t$ to $t+T_{r}$, and then earn a skilled wage flow $(\theta(t)-$ $\Gamma) w_{H}(s)$ at all dates $s \in\left[t+T_{r}, t+D\right]$, which implies that at time $t$ there will exist an ability threshold $\theta_{0}(t) \in[\Gamma, 1]$ below which the individual decides to work as an unskilled.

21 Dinopoulos and Segerstrom (1999) have first developed the overlapping generations education framework followed here. Boucekkine et al. $(2002,2007)$ recently studied population and human capital dynamics in continuous time and off steady states and numerically calibrated in a way methodologically more similar to ours. 
Threshold $\theta_{0}(t)$ solves the following equation:

$$
\int_{t}^{t+D} e^{-\int_{t}^{s} i(\tau) d \tau} d s=\left(\theta_{0}(t)-\Gamma\right) \int_{t+T r}^{t+D} e^{-\int_{t}^{s} i(\tau) d \tau} w_{H}(s) d s,
$$

obtaining

$$
\theta_{0}(t)=\Gamma+\frac{\int_{t}^{t+D} e^{-\int_{t}^{s} i(\tau) d \tau} d s}{\int_{t+T r}^{t+D} e^{-\int_{t}^{s} i(\tau) d \tau} w_{H}(s) d s} .
$$

Since in a steady state $i(t)=\rho+g$, the steady state level of $\theta_{0}(t)$ is

$$
\theta_{0}=\Gamma+\frac{1-e^{-(\rho+g) D}}{\left[e^{-(\rho+g) T r}-e^{-(\rho+g) D}\right] w_{H}},
$$

where $w_{H}$ denotes the steady state skill premium.

The evolution of the mass of unskilled labour per-capita responds negatively to expected education incentives. In fact, we prove in Unskilled labor supply section in Appendix that

$$
i(t)=b \theta_{0}(t)-b e^{-g D} \theta_{0}(t-D)-g l(t) .
$$

Notice that this is a delayed differential equation, which needs a continuum of initial conditions, back to a period of length $D$.

The percapita stock of human capital, $h(t) \equiv H(t) / N(t)$, evolves according to the evolution of $\theta_{0}(t)$, obeying Eq. (24). As a consequence, in Human capital section in Appendix, we prove that

$$
\begin{aligned}
\dot{h}(t)= & -g h(t)+\frac{b}{2} e^{-g T r}\left(1-\theta_{0}(t-T r)\right)\left(1+\theta_{0}(t-T r)-2 \Gamma\right) \\
& +\frac{b}{2} e^{-g D}\left(1-\theta_{0}(t-D)\right)\left(1+\theta_{0}(t-D)-2 \Gamma\right),
\end{aligned}
$$

which is a delayed differential equation, requiring a continuum of initial conditions in the interval $[-D, 0]$.

\section{Equilibrium}

In equilibrium, households choose consumption and education to maximize utility taking prices as given, manufacturing firms compete in each industry choosing their prices; basic research firms, applied research firms, and basic research patent holders maximize their profits taking prices as given; all markets clear; all arbitrage opportunities have been exploited; the stock variables evolve according to their law of motion. More specifically, we focus on a symmetric equilibrium, which implies that all industry variables are equal: it consists in a time path of quantities $\beta(t), h(t), l(t), x(t), y(t), n_{B}(t), n_{A}(t)$, and $m\left(A_{0}(t)\right)$, a time path of prices $r(t), v_{B}(t), v_{L}^{0}(t), v_{L}^{1}(t), w_{H}(t), \pi(t)$, and a time path of education ability threshold level $\theta_{0}(t)$, for all $t \geq 0$, consistent with the initial conditions $\beta(0), m\left(A_{0}(0)\right), h(s)_{s \in[-D, 0]}$, $l(s)_{s \in[-D, 0]}$, such that at each instant of time $t \geq 0$, Eqs. (3), (4), (24), (8), (26), (11), (9), (27), (12), (13), (14a), (14b), (14c), (14d), and (14e) are satisfied.

In a steady state the time derivatives of the percapita variables of the above-mentioned equations are constant, and we can state: 
Definition A steady state equilibrium is a vector $\left[\beta, h, l, x, y, n_{B}, n_{A}, m\left(A_{0}\right), r, v_{B}, v_{L}^{0}\right.$, $\left.v_{L}^{1}, w_{H}, \pi, \theta_{0}\right] \in R_{++}^{15}$ which satisfies the following equations:

$$
\begin{aligned}
\beta= & \bar{\beta} \\
r= & \rho \\
\theta_{0}= & \Gamma+\frac{1-e^{-(\rho+g) D}}{\left[e^{-(\rho+g) T r}-e^{-(\rho+g) D}\right] w_{H}} \\
l= & \theta_{0} \\
x= & \frac{1}{w_{H}}\left(\frac{\alpha}{1-\alpha}\right) l \\
y= & \frac{1}{w_{H}^{\alpha}}\left(\frac{\alpha}{1-\alpha}\right)^{\alpha} l \\
\pi= & (\gamma-1) \frac{1}{1-\alpha} l \\
h= & b \frac{\left[e^{g(-T r)}-e^{g(-D)}\right]\left(1-\theta_{0}\right)\left(1+\theta_{0}-2 \Gamma\right)}{2 g} \\
& x+m\left(A_{0}\right) n_{B}+\left(1-m\left(A_{0}\right)\right) n_{A}=h \\
& \left(1-m_{0}\right) \lambda_{1}\left(n_{A}\right)^{1-a}=m\left(A_{0}\right) \lambda_{0}\left(n_{B}\right)^{1-a} \\
& w_{H}=\lambda_{0} n_{B}^{-a} v_{B} \\
& \quad r v_{B}=\lambda_{1} n_{A}^{1-a}\left(\beta v_{L}^{0}-v_{B}\right) \\
& w_{H}=\lambda_{1} n_{A}^{-a}(1-\beta) v_{L}^{0} \\
& \quad r v_{L}^{0}=\pi-\lambda_{0} n_{B}^{1-a}\left(v_{L}^{0}-v_{L}^{1}\right) \\
& \quad r v_{L}^{1}=\pi-\lambda_{1} n_{A}^{1-a} v_{L}^{1} .
\end{aligned}
$$

For the interpretation of Eqs. (36)-(38e), the reader is referred to the analysis of the case without endogenous skill acquisition.

\subsection{Steady state properties}

The steady state equations are highly non-linear, and an analytical closed-form solution is unattainable. We have resorted to numerical simulations of the model and have found regularities across steady states. In particular, strengthening the steady state patent protection of basic research, as parameterized by an increase in $\bar{\beta}$ from 0 to 1 leads to: an inverted Ushaped relationship in basic research, both per-industry-i.e. $n_{B}$-and in the aggregate-i.e. $n_{B} m\left(A_{0}\right)$; and a decrease in industry applied $\mathrm{R} \& \mathrm{D} n_{A}$. This is clearly visible in Fig. 3 , which reports a representative case:

In the figure, we also report the effects of $\bar{\beta}$ on $m\left(A_{0}\right)$. The parameters chosen for this simulation are in line with the literature. In particular, we have set the intra-sectorial congestion parameter $a=0.3$, consistently with Jones and Williams' $(1998,2000)$ calibrations; the mark-up $\gamma=1.68$, consistently with what estimated by Roeger (1995) and Martins and Scarpetta (1996). Parameter $\alpha=0.1$ - the share of high skilled workers ${ }^{22}$ in manufacturing production, is consistent with Berman et al. (1994). Parameters $D=40, n=0.01, T_{r}=4$,

22 We here restrict to the share of technician workers in manufacturing in the late 80 s, as indicated by Berman et al. (1994). We are ignoring other white collars, though our simulations are quite robust to alternative specifications. 

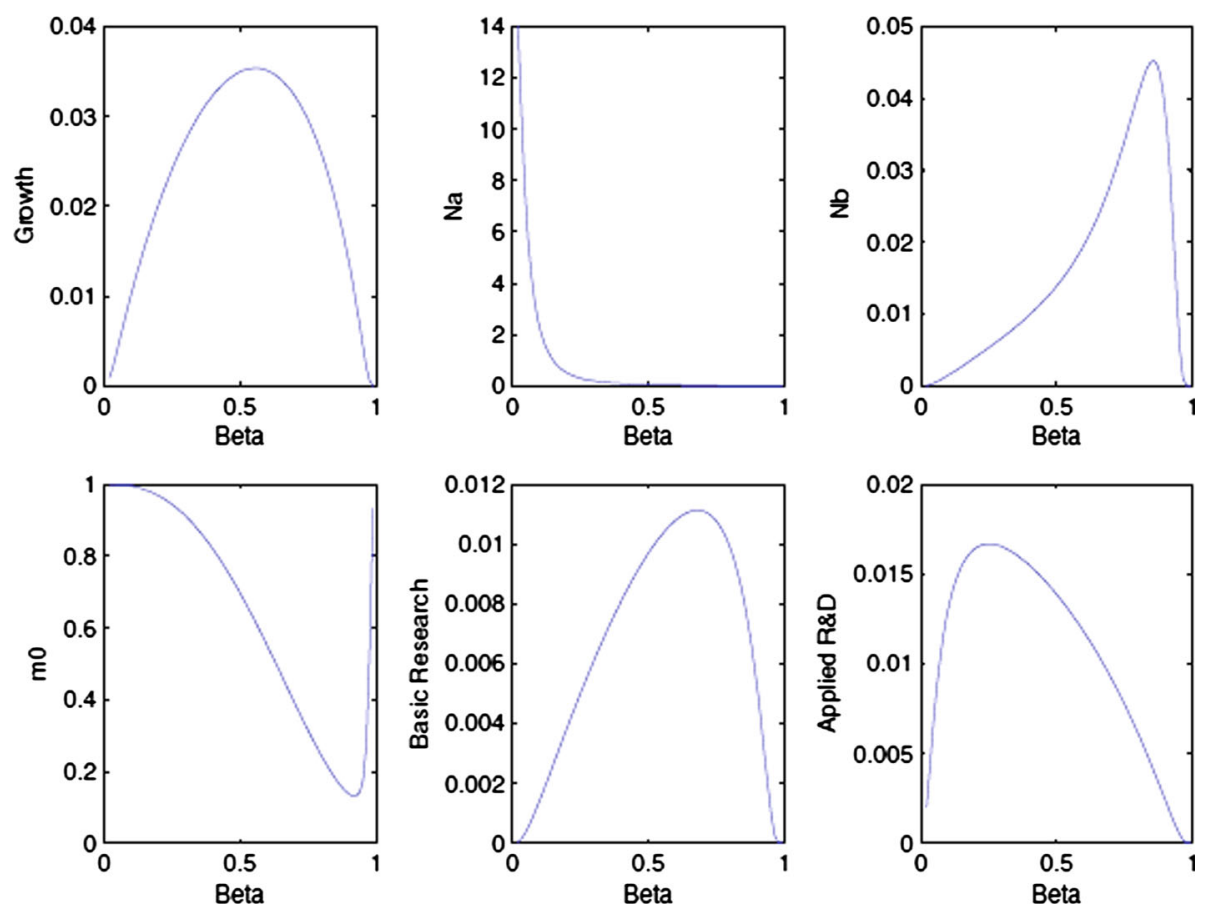

Fig. 3 Long-term comparative statics

$\Gamma=0.75$ follow Dinopoulos and Segerstrom (1999). For the real rate of return on consumer assets, we adopt the usual $\rho=0.05$, common in the literature. We set benchmark values of our new parameter at $\lambda_{0}=\lambda_{1}=1, \varphi=0.01$, but results are robust to huge variations of them.

The reason for the observed patterns is the following: when $\bar{\beta}$ is low basic research is less rewarded, while applied research is highly incentivized. Hence basic research is low and applied research is high. As $\bar{\beta}$ increases, the share of the final value of the patent accruing to applied research declines, which explains the drop in $n_{A}$. Quite interestingly, this drop is not specific of the current example, but holds more generally; in fact, we can prove the following:

Lemma 1 The steady state equilibrium level of applied research per-industry, $n_{A}$, always decreases in $\bar{\beta}$.

\section{Proof See Appendix.}

Notice that $n_{A}$ is the amount of applied R\&D in a sector in which applied R\&D is carried out, that is where a research tools exists: there are $m\left(A_{1}\right)=1-m\left(A_{0}\right)$ such sectors, and this mass is endogenous. As $\bar{\beta}$ gets close to zero, basic research nearly disappears, but $n_{A}$ keeps increasing.

Conversely, the reward to basic research increases only as long as applied research is not too low: as is clear from Eq. (38b), $v_{B}$ increases in $\bar{\beta}$ and in $n_{A}$. If $\bar{\beta}$ gets too close to $1, n_{A}$ drops towards 0 , along with $v_{B}$. This complementarity between applied research and basic research is responsible for the observed non-monotonic relationship. Hence, while $n_{A}$ is conditional on a research tool's already existing, and therefore independent of $n_{B}, n_{B}$ needs to rely on the future $n_{A}$ in order to have chances of completion. 

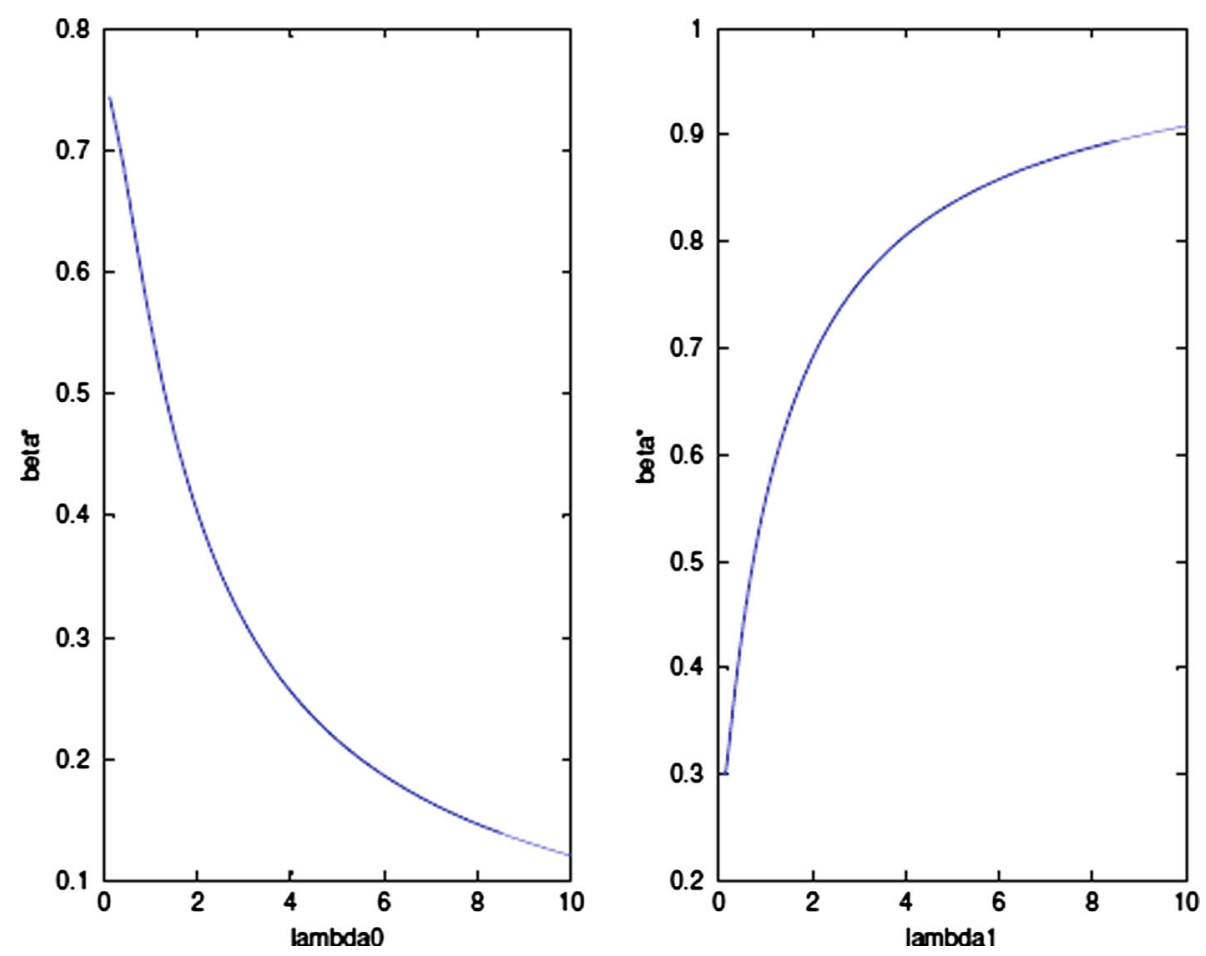

Fig. 4 Growth-maximizing $\beta$ s

As a consequence, $m\left(A_{0}\right)$ is high at low levels of $\bar{\beta}$ and it is low at high levels of $\bar{\beta}$. However, when $\bar{\beta}$ is very close to 1 , the drop in applied research can make $m\left(A_{0}\right)$ higher again. Aggregate applied research, i.e. $n_{A}\left(1-m\left(A_{0}\right)\right)$, inherits the combination of the comparative statics properties of $n_{A}$ and $1-m\left(A_{0}\right)$.

For these reasons, strengthening patent protection of basic research, that is an increase in $\bar{\beta}$, increases the long-run aggregate innovation rate when the initial level of $\bar{\beta}$ is low. Conversely, an increase in $\bar{\beta}$ decreases the long-run innovation rate when the initial level of $\bar{\beta}$ is high. Hence an interior level of $\bar{\beta}$ maximizes the aggregate innovation rate-equal to 0.5490 in the example of Fig. 3.

The growth-maximizing level of $\bar{\beta}$, denoted $\bar{\beta}^{*}$, depends on all the parameters in the model. Quite important are the basic and applied R\&D productivity parameters, $\lambda_{0}$ and $\lambda_{1}$ : their effect on $\bar{\beta}^{*}$ is plotted in Fig. 4.

As the reader can see, $\bar{\beta}^{*}$ increases with $\lambda_{1}$ and decreases with $\lambda_{0}$ : the more difficult basic research relative to applied research, the higher its share of the final patent value should be.

We can characterize the system for a special case, with its camparative statics properties locally carrying out by continuity, as shown in the next section.

\section{Analysis of a benchmark special case}

The analytical results of this section are obtained under the assumption that $\rho=0$; since all steady state equations are continuous in all variables and parameters, its comparative statics results continue to hold in a positive neighborhood where $\rho>0$. Consequently, in the steady 
state the real interest rate is $i=r+g$, and our assumption implies $i=g>0$. It is useful to notice that, strictly speaking, the transversality condition (4) continues to hold in this case. While the utility functional ( 1 ) does not converge as $\rho \rightarrow 0$, it obviously does hold in a continuum of economies ${ }^{23}$ associated with $\rho>0$.

Equation (14b), the steady state definition and $r=0$ imply:

$$
v_{B}=\beta v_{L}^{0} .
$$

From this and from Eqs. (14a) and (14c):

$$
n_{A}=\left(\frac{\lambda_{1}}{\lambda_{0}} \frac{1-\beta}{\beta}\right)^{\frac{1}{a}} n_{B} .
$$

From Eqs. (14d) and (14e), the steady state definition and $r=0$, and Eq. (40), we can write:

$$
v_{L}^{0}=\left[\left(\frac{\lambda_{1}}{\lambda_{0}}\right)^{\frac{1}{a}}\left(\frac{1-\beta}{\beta}\right)^{\frac{1-a}{a}}+1\right] v_{L}^{1} .
$$

Imposing the steady state into (12) and using (40) yields:

Lemma 2 If $\rho=0$, the steady state equilibrium fraction of industries where basic $R \& D$ is active is

$$
m\left(A_{0}\right)=\frac{1}{1+\left(\frac{\lambda_{0}}{\lambda_{1}}\right)^{\frac{1}{a}}\left(\frac{\beta}{1-\beta}\right)^{\frac{1-a}{a}} .}
$$

Lemma 2 indicates that the higher the difficulty of basic research (applied research), i.e. the lower $\lambda_{0}$ (the lower $\lambda_{1}$ ) the higher the fraction of sectors where basic (applied) R\&D is needed.

This has implications for the innovation-enhancing regulation:

Proposition 1 If $\rho=0$, the growth maximizing upstream inventor share, $\beta^{*}$, of the final good patent value is equal to:

$$
\beta^{*}=\frac{\lambda_{1}}{\lambda_{0}+\lambda_{1}}=\frac{1}{\frac{\lambda_{0}}{\lambda_{1}}+1} .
$$

\section{Proof See Appendix}

Proposition 1 states that the innovators should be rewarded proportionally more in the stages of $\mathrm{R} \& \mathrm{D}$ where innovation is harder to achieve. Plugging $\beta^{*}$ into Eq. (40) implies that at the growth-maximizing policy $n_{A}=n_{B}$. Hence the innovation-maximizing share is higher in the industry where (equilibrium) innovation is slower-expected times $\frac{1}{\lambda_{0} n_{B}^{1-a}}>\frac{1}{\lambda_{1} n_{A}^{1-a}}$ imply $\beta^{*}>0.5$ and vice-versa. This is in line with our more general numerical results, as shown, for example, in Fig. 3. Interestingly, setting $\beta=\beta^{*}$ in Eq. (42) gives $m\left(A_{0}\right)=\beta^{*}$. Setting $\beta=m\left(A_{0}\right)$ in Eq. (42) delivers a unique solution in $[0,1]$ : exactly $\beta=\beta^{*}$.

It is important to notice that here $\beta^{*}$ is common across industries without the risk of a "one-size-fits-all" loss (Chu 2010b) only because all industries are symmetric. However, with heterogenous industries, it would be interesting to generalize this result.

23 We have also checked that the equilibrium values of the endogenous variables change continuously by undertaking numerical simulations. 


\subsection{Hosios condition interpretation}

We can draw a similarity between the optimal basic researcher's sharing rule expressed by Eq. (43) and Hosios (1990) constrained efficiency condition in Diamond-Mortensen-Pissarides search and matching models. Of course, here we do not have unemployed searching for jobs and vacancies waiting for unemployed, but basic researchers searching for research tools upon which applied researchers search for completions. However, as in search and matching models, both research activities exert a positive externality on the other type of activity and a negative externality (due to congestion) on itself, and in a steady state equilibrium $n_{A}$ and $n_{B}$ do not change over time. ${ }^{24}$ Therefore we could reinterprete the discovery of a new final good as a successful "match" between a basic research unit of human capital and an applied research unit of human capital.

Under this interpretation, the number of successful matches between a basic research unit (of human capital) and an applied research unit is given by the aggregate innovation rate, which, using Eq. (37), in the steady state is equal to

$$
g=\frac{\lambda_{0} n_{B}^{1-a} \lambda_{1} n_{A}^{1-a}}{\lambda_{0} n_{B}^{1-a}+\lambda_{1} n_{A}^{1-a}} .
$$

which shows that our "matching function" has decreasing returns to scale due to intraindustry research congestions. While this precludes the application of original Hosios (1990) rule, which requires CRS, we can use Ellison et al. (2013) result, which shows how Hosios' conditions must be generalised to non-constant returns to scale.

To achieve that, notice that the right hand side of Eq. (44) is a monotone transformation, namely $\Phi(\cdot)=\frac{\lambda_{0} \lambda_{1}}{\lambda_{0}+\lambda_{1}}(\cdot)^{1-a}$, of the following CRS aggregate search activity function ${ }^{25}$

$$
M\left(n_{B}, n_{A}\right)=\left[\frac{\lambda_{0}+\lambda_{1}}{\lambda_{0} \lambda_{1}}\left(\frac{\lambda_{0} n_{B}^{1-a} \lambda_{1} n_{A}^{1-a}}{\lambda_{0} n_{B}^{1-a}+\lambda_{1} n_{A}^{1-a}}\right)\right]^{\frac{1}{1-a}} .
$$

Hence our matching function $\Phi\left(M\left(n_{B}, n_{A}\right)\right)$ is homothetic and has decreasing returns to scale.

Applying to Ellison et al.'s (2013) Corollary 1 to our framework, the generalized Hosios' condition dictates an optimal share of basic research $\beta_{B}^{\text {Hosios }}$ and of applied research $\beta_{A}^{\text {Hosios }}$ which satisfy:

$$
\begin{aligned}
& \beta_{B}^{\text {Hosios }}=\eta_{M / n_{B}} \eta(g)=\eta_{M / n_{B}}(1-a) \\
& \beta_{A}^{\text {Hosios }}=\eta_{M / n_{A}} \eta(g)=\eta_{M / n_{A}}(1-a),
\end{aligned}
$$

where $\eta(M)=\frac{M \Phi^{\prime}(M)}{\Phi(M)}=1-a$ is the elasticity of the matching function, $g$, with respect to aggregate search activity, $M$; and the elasticities with respect to basic and applied research are denoted ${ }^{26} \eta_{M / n_{B}}$ and $\eta_{M / n_{A}}$. In turn, the elasticity of function $M$ with respect to $n_{B}$, $\eta_{M / n_{B}}$, is equal to:

\footnotetext{
24 Hence it does no harm to abstract from R\&D sequentiality and imagine both activities to be taken simultaneously. This is also facilitated by the zero-interest rate assumption of this simpler model—which (along with the steady state) was indeed assumed by Hosios (1990) original paper.

25 We adopt Ellison et al. (2013) definition of the CRS function $M$ (which they denote $m$ ) as "aggregate search activity", converted to matches by transformation $\Phi$. Notice that our set up satisfies $M(1,1)=1$ and $\Phi(0)=0$, as required by Ellison et al. (2013).
}

26 They correspond to $\alpha$ and $1-\alpha$ of Ellison et al. (2013). 


$$
\eta_{M / n_{B}}=\frac{\lambda_{1}}{\lambda_{0}\left(\frac{n_{B}}{n_{A}}\right)^{1-a}+\lambda_{1}},
$$

while the elasticity with respect to $n_{A}, \eta_{M / n_{A}}$, is equal to:

$$
\eta_{M / n_{A}}=\frac{\lambda_{0}}{\lambda_{0}+\lambda_{1}\left(\frac{n_{B}}{n_{A}}\right)^{a-1}} .
$$

Clearly $\eta_{M / n_{B}}$ and $\eta_{M / n_{A}}$ sum to 1 due to the constant returns of function $M$.

It is easy to re-obtain the equivalent of Eq. (40) with the shares of basic, respectively applied, R\&D denoted $\beta_{B}^{\text {Hosios }}$, respectively $\beta_{A}^{\text {Hosios }}$, instead of $\beta$ and $1-\beta$ :

$$
\frac{n_{B}}{n_{A}}=\left(\frac{\lambda_{0}}{\lambda_{1}} \frac{\beta_{B}^{\text {Hosios }}}{\beta_{A}^{\text {Hosios }}}\right)^{\frac{1}{a}},
$$

where we are now not assuming $\beta_{B}^{\text {Hosios }}+\beta_{A}^{\text {Hosios }}=1$ for reasons that will become clear shortly.

Plugging (49) into Eqs. (47) and (48), and plugging them back in Eqs. (45) and (46), gives the locally optimal shares according to the generalized Hosios conditions:

$$
\begin{aligned}
& \beta_{B}^{\text {Hosios }}=(1-a) \frac{\lambda_{1}}{\lambda_{0}+\lambda_{1}}=(1-a) \beta^{*}, \text { and } \\
& \beta_{A}^{\text {Hosios }}=(1-a) \frac{\lambda_{0}}{\lambda_{0}+\lambda_{1}}=(1-a)\left(1-\beta^{*}\right) .
\end{aligned}
$$

Equations (45) and (46) 27 imply that the generalized Hosios conditions-which requires that in a locally efficient decentralized matching the surplus shares are proportional to the elasticities of matching - provides a similar result as our growth-maximizing sharing rule $\beta^{*}$ found in the previous section. However, there is a correction, due to the additional negative externality of R\&D "market size" underlying the decreasing returns of our "matching function" (44). In such a case, the optimal surplus shares do not sum to one because under "decreasing returns to scale, the surplus must be taxed in order to give agents appropriate search incentives." (Ellison et al. 2013). Quite interestingly, the mere application of the original Hosios (1990) rule, avoiding to rescale researchers' shares by $1-a$, would deliver exactly our previous growth maximizing $\beta^{*}$. Hence while the Hosios rule, literally taken, would align incentives to correct relative market tightness, the rescaling provided by Eq. (50) also corrects for the absolute size externality.

\subsection{An empirical "rule of thumb"}

The special case we have just analyzed allows us to gain some insight on aggregate empirical evidence. In particular, from the knowledge of the basic to applied research ratio, $B A R$, we can easily obtain approximations for the actual values of $\beta$. In fact, Eqs. (40) and (42) yield:

27 Ellison et al.'s (2013) Corollary 1 also requires an additional technical condition (Eq. 27), which in our framework becomes $\frac{a}{1-a}<\frac{\lambda_{1}}{\lambda_{0}}$. It will be valid as long as the congestion parameter is not too high and the productivity parameter of applied $\mathrm{R} \& \mathrm{D}$ is not too low relative to that of the basic research. 
Table 1 Data for Eq. (Beta)

Data on US Basic Research, US Applied Research, and US "Beta" (upstream bargaining power)

\begin{tabular}{|c|c|c|c|}
\hline Year & Basic R\&D & Applied R\&D & Beta \\
\hline 1981 & 18,492 & 31,267 & 0.371631 \\
\hline 1982 & 19,221 & 32,877 & 0.368939 \\
\hline 1983 & 20,624 & 35,238 & 0.369196 \\
\hline 1984 & 22,306 & 37,564 & 0.372574 \\
\hline 1985 & 23,951 & 41,251 & 0.367335 \\
\hline 1986 & 27,255 & 43,280 & 0.386404 \\
\hline 1987 & 28,536 & 43,158 & 0.398025 \\
\hline 1988 & 29,538 & 44,079 & 0.401239 \\
\hline 1989 & 31,489 & 46,430 & 0.404125 \\
\hline 1990 & 31,896 & 48,333 & 0.397562 \\
\hline 1991 & 36,302 & 51,674 & 0.412635 \\
\hline 1992 & 36,068 & 49,568 & 0.421178 \\
\hline 1993 & 36,744 & 47,661 & 0.43533 \\
\hline 1994 & 37,123 & 45,845 & 0.447438 \\
\hline 1995 & 36,315 & 50,206 & 0.419725 \\
\hline 1996 & 39,475 & 51,957 & 0.431742 \\
\hline 1997 & 43,664 & 55,058 & 0.442292 \\
\hline 1998 & 41,366 & 54,218 & 0.432771 \\
\hline 1999 & 44,872 & 59,938 & 0.428127 \\
\hline 2000 & 48,186 & 63,885 & 0.42996 \\
\hline 2001 & 52,605 & 70,735 & 0.426504 \\
\hline 2002 & 56,295 & 55,096 & 0.505382 \\
\hline 2003 & 59,584 & 65,203 & 0.477486 \\
\hline 2004 & 59,648 & 71,775 & 0.453863 \\
\hline 2005 & 61,321 & 70,001 & 0.466951 \\
\hline 2006 & 60,065 & 74,333 & 0.446919 \\
\hline 2007 & 61,776 & 78,661 & 0.439883 \\
\hline 2008 & 63,487 & 68,905 & 0.479537 \\
\hline 2009 & 65,197 & 66,419 & 0.495359 \\
\hline 2010 & 66,908 & 71,666 & 0.482833 \\
\hline 2011 & 68,619 & 71,220 & 0.4907 \\
\hline
\end{tabular}

$$
\begin{aligned}
B A R & =\frac{n_{B} m\left(A_{0}\right)}{n_{A}\left[1-m\left(A_{0}\right)\right]}=\left(\frac{\lambda_{1}}{\lambda_{0}} \frac{1-\beta}{\beta}\right)^{\frac{-1}{a}}\left(\frac{\lambda_{0}}{\lambda_{1}}\right)^{\frac{-1}{a}}\left(\frac{\beta}{1-\beta}\right)^{-\frac{1-a}{a}} \\
& =\frac{\beta}{1-\beta}
\end{aligned}
$$

which implies

$$
\beta=\frac{B A R}{1+B A R} .
$$

Given its extremely simple formulation, we can easily provide some of its values in the reported Table 1. 


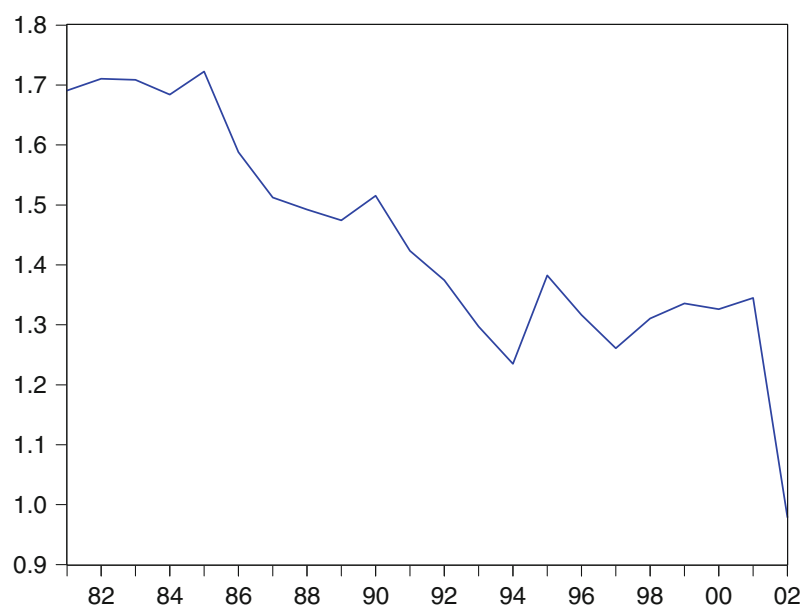

Fig. 5 Applied R\&D/basic R\&D in the US. Data from National Science Foundation (2013)

Therefore, according to the data ${ }^{28}$ of Table 1 , in 1981 our calibrated $\beta$ would be equal to $37.16 \%$, while in 2002 it would have climbed up to its highest ever level of $50.53 \%$, taken on by $\beta$ right in the year of the Madey vs. Duke University Federal Circuit's decision. After that, it has declined below $50 \%$, including becoming $46.69 \%$ in the year of the Merck vs. Integra Lifesciences (2005) ruling. ${ }^{29}$ Of course, these calibrated values are to be taken as a "rule of thumb" indicator of the bargaining power of the upstream innovator: off-steady state and with changing interest rates they ought to be adjusted. Equation (Beta)'s shortcut may offer a microfounded and yet easy-to-compute approximation to practitioners and policy-makers only to stimulate further investigation.

A stricking consequence can be viewed in the NSF data on basic and applied research, which suggest that, while both types of R\&D have increased over time (due to population growth, market size growth, surge in higher education, etc.), applied research relative to basic research has steadily and considerably declined in that period, as shown in Fig. 5 passing from 1.69 in 1981 to 0.99 in 2002, year of its lowest peak ever: a massive reduction of more than one third, with basic research overtaking applied research for the first time at least since 1953.

In the model so far we have been deriving results under the working assumption that the whole basic research is done by profit-maximizing firms. However, as Gersbach et al. (2010, 2012) and Akcigit et al. (2012) document, a large part of basic research is carried out by public institutions: according to the NSF, in 2011, total basic research investment in the US was $\$ 69,218$ (2005 constant dollars). ${ }^{30}$ Only about $20 \%$ of this $(\$ 14,611$ milions) is done by the profit seeking business sector. Can our theory, and our empirical rule of thumb, be reconciled with this important stylized fact? It easily can, as long as also the private sector undertakes some basic research ${ }^{31}$ and entry into the R\&D activity is unrestricted. In fact,

\footnotetext{
28 Based on National Science Foundation (2013), Table 3 ("U.S. applied research expenditures", "All Sources") and Table 4 ("U.S. applied research expenditures", "All Sources"), in million constant 2005 dollars: 1953-2011.

29 Which reopened the door to the research exemption doctrine at least for the pharmaceutical sector.

30 http://www.nsf.gov/statistics/nsf13318/.

31 That is, if publicly-funded basic research is not so huge to completely crowd the private R\&D out of the market, so that Eq. (14a) is still valid.
} 
assuming that a fraction of basic research per-sector is performed publicly would imply that our steady state equations would incorporate one additional equation:

$$
n_{B}=n_{B}^{g o v}+n_{B}^{p r i v}
$$

where $n_{B}^{g o v}$ is the (per-capita amount of) publicly funded basic R\&D labour per-sector and $n_{B}^{\text {priv }}$ is the privately funded basic R\&D labour per-sector. Notice that $n_{B}^{g o v}$ would be exogenous, ${ }^{32}$ while $n_{B}^{\text {priv }}$ would be the new endogenous variable. In any equilibrium with $n_{B}^{\text {priv }}>0$ - which is quite realistic - all the other equilibrium equations would still hold, ${ }^{33}$ with no change in the aggregate results.

\section{Strictly blocking patents}

The present setup with basic and applied $R \& D$ is suitable to analyze a crucial issue: the patenting of basic research may hinder applied innovations because even basic concepts are patented which potentially precludes new innovations. Clearly, the incumbent monopolist in the corresponding final good sector is the natural suspect of such anti-innovative behavior. In fact, by appropriating the patent on a basic research result and stopping R\&D it would eliminate expected obsolescence on its product, causing its value to jump up to $\frac{\pi}{r}$, because profits $^{34}$ last forever. In the steady state, the incumbent monopolist will buy the patent in order to block innovation in that sector if its willingness to pay for the research tool is higher than the outsiders' reservation price, that is if and only if:

$$
v_{B} \leq \frac{\pi}{r}-v_{L}^{1}
$$

Equation (51) is equivalent to $r v_{L}^{1}-\pi \leq-r v_{B}$. This and Eq. (14e) imply that

$$
-\lambda_{1} n_{A}^{1-a} v_{L}^{1} \leq-r v_{B} .
$$

Using Eq. (14b), the above inequality becomes equivalent to:

$$
v_{B}+v_{L}^{1} \geq \beta v_{L}^{0} \text {. }
$$

Quite interestingly, for the benchmark special case of the previous section, due to Eq. (39), the inequality (52) is certainly satisfied with strict inequality. While the benchmark special case is only valid as a mathematical approximation of the steady state equilibrium equations, by continuity the following holds:

32 Alternatively, we could assume that a given level of public expenditure $G$ is planned, with its actual amount per-sector $n_{B}^{\text {gov }}=\frac{G}{m\left(A_{0}\right) w_{H}}$ being determined endogenously. As long as $n_{B}^{\text {gov }}$ does not exceed the level of $n_{B}$ which satisfies free entry condition (14a), our equilibrium will be unchanged.

33 Of course, in so doing we are assuming that the government funded R\&D is equally productive and that government agencies wish to derive the deserved income share $\beta$ of the value of the private profits generated by their innovations. This is certainly possible after 1980 Bayh-Dole and Stevenson-Wydler acts. Moreover, the Reagan administration strongly encouraged the patentability of research outcomes obtained by the use of public funds as a vehicle to find new sources of government revenues alternative to taxation. Our zero-profit conditions clearly allow this public R\&D to self-finance itself.

34 The profit of the blocking monopolist is always the same, $\pi$, regardless of the progressively lower relative quality of its good. This is a consequence of our assumed Cobb-Douglas preference structure, characterized by unit elasticity of substitution across varieties. If the elasticity of substitution was higher (lower) than 1 the profits would gradually decline (increase). A more complete model, beyond the scope of this paper, would also consider a realistic finite patent life. 
Lemma 3 In an open right neighborhood of $\rho=0$, the steady state equilibrium implies an attempt of incumbents to block innovation.

This points to a serious problem in the patenting of basic (or applied) research: a danger, which may become true if the courts are not ready to detect such a practice. ${ }^{35}$ In a well functioning judicial system, according to Maurer and Scotchmer (2004, p. 90), courts “usually approve arrangements that remove blocking patents so that firms can bring technologies to market." The typical arrangement is the compulsory licensing of the patented innovative tool. In a recent paper, Galasso and Schankerman (2013) find robust evidence of the blocking effect of patents held by large firms (the "incumbents" of our paper) to downstream innovation undertaken by small firms (the freely entrant applied R\&D firms of our model): when some of these patents are invalidated by the courts, follow on innovation will significantly increase. They also find that this problem afflicts the medical instruments and biotechnology, electronics, and computers sectors. Given the incentives to block of potentially powerful incumbent patent holders highlighted in this section, we conclude that in the presence of patentable basic research results the courts play a crucial role in protecting innovative activity.

\section{Insights from transitional simulations}

In this section we will focus on the transitional dynamics of our model. In particular, we will show that when the bargaining power of the basic researcher, i.e. $\beta$, increases, it always looks bad at first. Even if it is good for long-run growth, in the short- or even medium-run it presents itself as harmful to growth. In order to show the mechanism at work, we report two representative trajectories obtained for the endogenous variables following the announcement of a regime change in the law of motion of $\beta$. This corresponds to a sudden change in the steady state value of $\bar{\beta}$, which gradually drives, via Eq. (13), the system towards the new steady state. We ran several discrete approximations of the differential equations (12), (16), (14b), (14d), (14e), (53), (54), (55), (56), and cross-equations restrictions (8), (10), (11), (14a), (14c), (70), and (59), obtaining remarkably robust results. ${ }^{36}$ We will keep the same parameters as used in Fig. 3. As for the common law adjustment parameter, we have set $\psi=0.9$.

We assume that the economy begins with a steady state associated with a given value of $\bar{\beta}$. Then $\bar{\beta}$ changes and the common law share of the basic research inventor starts to head towards its new steady state value.

In order to make different simulations comparable, we plot the trajectories of the deviations of the value of each variable from its initial steady state value, divided by its initial steady state value. For example, the "aggregate innovation rate" of the last subplot is the normalized deviation of the number of applied innovations per unit time, that is of $\left(1-m\left(A_{0}(t)\right)\right) \lambda_{1}\left(n_{A}(t)\right)^{1-a}$, from its initial steady state value.

Figure 6 assumes that, after a long term (40 periods) initial value of $\bar{\beta}=0.35$, it suddenly changes to $\bar{\beta}=0.5$. We conjecture that such a change will be beneficial for long-term growth. In fact, we know from Proposition 1 , that $\bar{\beta}=0.5$ would maximize growth for

\footnotetext{
35 This is an old problem in the history of patents. As reported by Scotchmer (2004, p. 14), "James Watt (d. 1819) used his patents to block high-pressure improvements... Watt's refusal to license competitors froze steam-engine technology for two decades." Fortunately, patent legal life was not as long as assumed in our model.

36 We have also simulated how the dynamic behavior changes if $\beta$ immediately jumps to the new steady state level, either expected or unexpected. The basic message of this section is robust to these variants.
} 

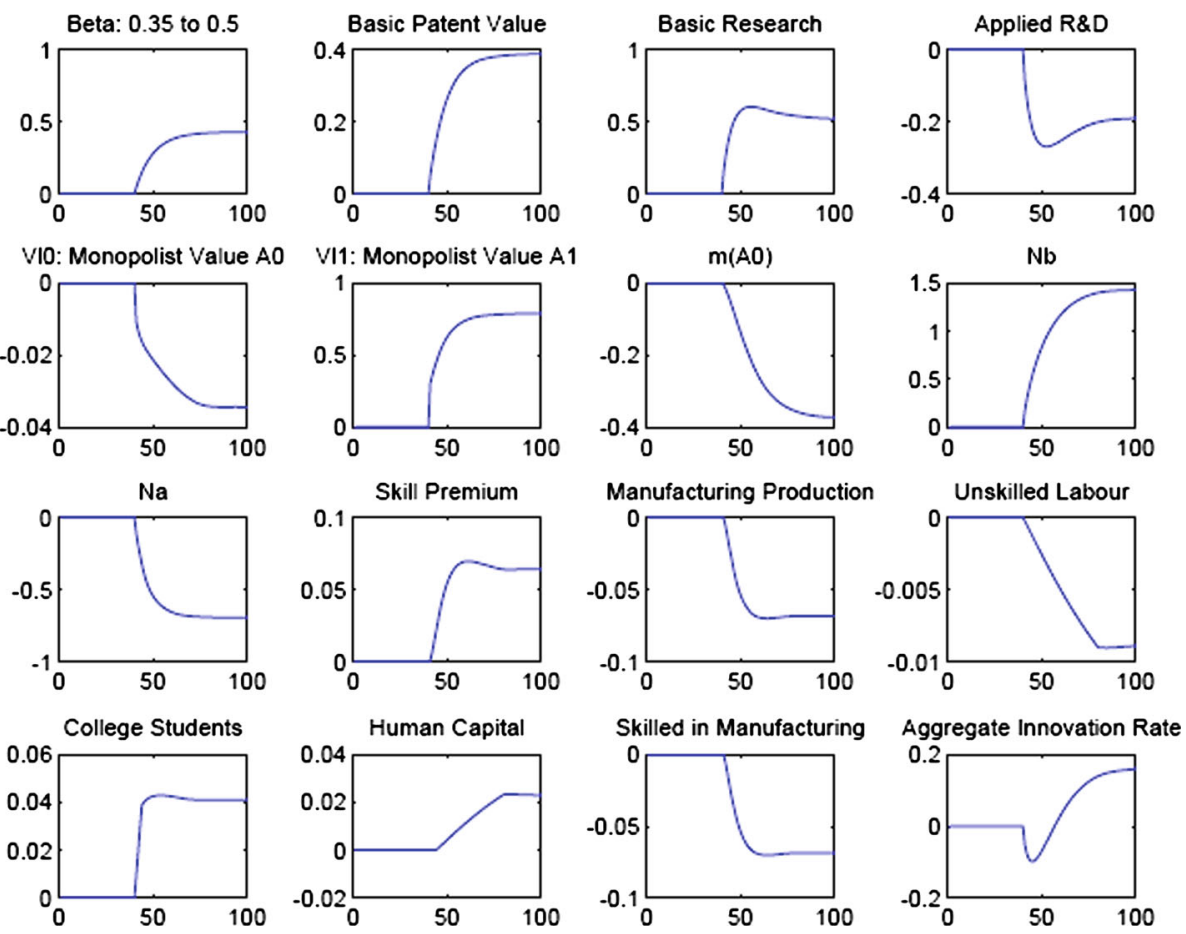

Fig. 6 Growth enhancing transition

perfectly patient agents. Since here $\rho>0$, we expect that impatient agents require basic research to be granted a larger share of the final patent value.

In fact, such a change is clearly growth improving from a steady state perspective: in the long run the new steady state is characterized by a higher rate of growth (i.e. of aggregate innovation), a higher skill premium, a higher fraction of population choosing to educate themselves ("college students"37) and a higher aggregate human capital. A higher value of $\beta$ means a higher fraction of the final invention appropriated by the basic researcher who invented its basic research pre-requisite and a lower value of the final product appropriated by the applied researcher who invented its commerciable version. Therefore basic research is becoming more profitable (higher "Basic Patent Value", $v_{B}$ ) and applied research less profitable. Consequently basic research employment increases - both at the aggregate ("Basic Research") and at the industry ("Nb") level—and applied research employment decreases both at the aggregate ("Applied R\&D") and at the industry ("Na") level. A consequence of this is that in the long run the stock market value $\left(v_{L}^{1}\right)$ of an $A_{1}$ monopolist increases-as it faces less obsolescence-while the long run stock market value ( $v_{L}^{0}$ ) of an $A_{0}$ monopolist gets closer to $v_{L}^{1}$, as it faces more obsolescence at the basic research stage. Since the positive incentives to basic $R \& D$ outweigh the negative incentives to applied $R \& D, R \& D$ as a whole becomes more profitable and more skilled labour is demanded. Therefore the skill wage, $w_{H}$, increases, thereby inducing a larger fraction of the population to enrol at university. This will gradually increase the supply of human capital and decrease the supply of unskilled labour.

37 To save space in the main text, we have relegated the analytics of the dynamics of the college students to College population section in Appendix. 
In the transitional dynamics, it is important to notice that as the change in the longterm court orientation $\bar{\beta}$ was not forecast by the private actors until period 40 , all the stock variables - $\beta(t), h(t), L(t)$, and $m\left(A_{0}(t)\right)$ - are predetermined, and for example by Eq. $(10), \pi(t)$ is constant. Hence only jump variables such as prices, wages, and employment change abruptly ${ }^{38}$ as soon as the transition starts. ${ }^{39}$ Being $\beta(t)$ monotonically increasing, the relative incentive of basic research gradually increases. However, the dynamics of $\beta(t)$ interacts with the intrinsically dynamic nature of the R\&D process, in a way that is not captured by the mere comparative statics of steady state analysis: in fact, the expectation of higher future values of $\beta(t)$ certainly favours current basic research-the completion of which will take place in the future-without harming current applied R\&D with the same intensity. In a discrete time approximation of our continuous time framework, we can imagine that basic and applied research complete - with an endogenous probability - in each period: the arrival of a still higher $\beta$ in period 41 is associated with the announcement of a higher $\beta$ next period (at 42) and later. However, next period's $\beta$ will not penalize current applied $R \& D$, while instead encouraging current basic research-which is promised a higher share of the future discovery. In our continuous time framework the same effect is at work via the right-continuous derivatives: $\beta(t)>0$ favours the expectedly later fruits of basic research more than it reduces the expectedly earlier gains of applied research. As a consequence, aggregate $R \& D$ is favoured, and the increase in the demand for $n_{B}(t)$ is matched by a lower decrease in the demand for $n_{A}(t)$, which implies that the difference $m\left(A_{0}(t)\right) n_{B}(t)-\left[1-m\left(A_{0}(t)\right)\right] n_{A}(t)$ increases and must be matched by a decrease in $x(t)$ : the increase in the net demand for R\&D labour can be satisfied only by a decrease in the manufacturing skilled-labour employment. This temporary excess demand for skilled labour is the reason for the immediate increase in the skill premium. As time passes, the increase in $w_{H}(t)$ will encourage marginally less able students to enroll to college, thereby leading to a future increase in the aggregate supply of human capital and to a partially offsetting effect on $w_{H}(t)$. However, as long as $\beta(t)$ keeps increasing the demand for R\&D

labour continues to grow, though the decline in $\beta(t)$ will eventually correct the previously mentioned intertemporal asymmetry that favoured basic research more than it disincentived applied R\&D.

Quite interestingly, the dynamics of human capital seems to have a kink at $t+80$, as does unkilled labour. This is due to the fact that the uniformely larger fraction of college students enrolled relative to the previous steady state (which is a result of the uniformely higher skill premium) drives up the human capital of the next cohorts (after the training delay) until the whole labour force has changed in finite time, i.e. in 40 periods. This implies that the growth of human capital and the decrease in unskilled labour will suddenly stop. If the evolution of the skill premium was not so strong the dynamics of the unskilled labour and of human capital would be more smoothed. ${ }^{40}$

In the generality of simulations we have undertaken, the aggregate innovation rate decreases in an initial period following the policy switch, whose length depends on the assigned parameters: the economic reason is that $\mathrm{R} \& \mathrm{D}$ is shifting upstream towards basic research, thereby reducing applied $R \& D$; this slows down the completion of existing basic

\footnotetext{
38 These variables are: $v_{B}, n_{B}, n_{A}, v_{L}^{0}, v_{L}^{1}, w$, and the variables simultaneously linked to them, i.e. "Basic Research", "Applied R\&D”, and $x$.

39 Even though this is not always clearly visible given the small units in Fig. 1. For example, "Basic Patent Value" has a fast increase in the period 41, and then its evolution becomes gradual, but this is hardly discernible by the eye. Similarly for "Basic Research".

40 As will be the case of Fig. 7.
} 

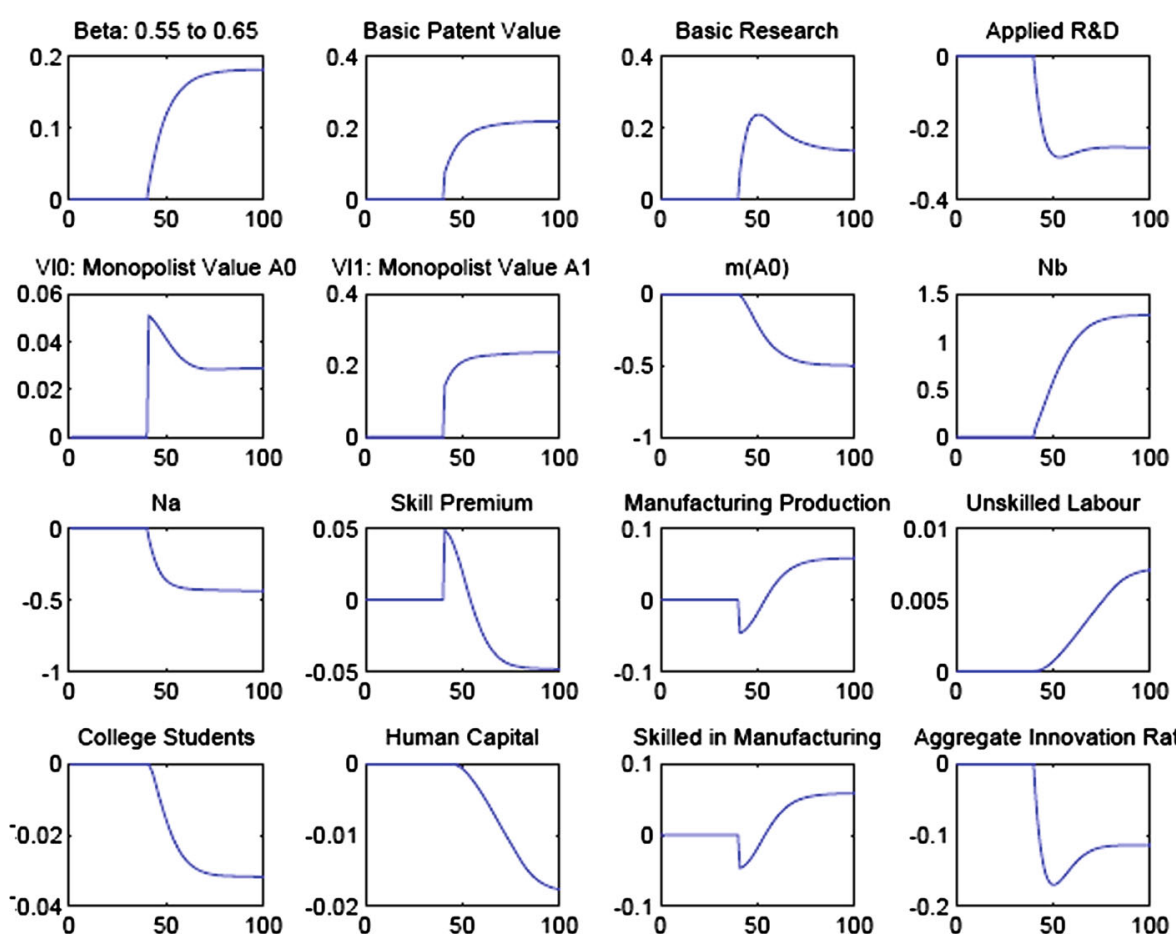

Skilled in Manufacturing
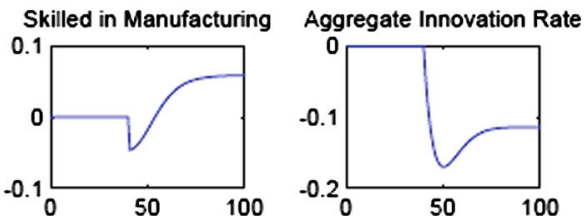

Fig. 7 Growth harming transition

research projects, which has a negative effect on innovation. However, in the case of Fig. 6, in the longer run, the increase in the flow of basic research results will more than compensate a thinner applied R\&D effort.

Our stylized representation suggests that policy makers should not lose their optimism about innovation enhancing policies based on shorter term R\&D reallocation effects coupled with the inevitably slow improvements in the population educational choices.

The transitional dynamics plotted in the next Fig. 7 is based on the assumption that the initial value of $\bar{\beta}$ was 0.55 and it suddenly changes to 0.65 . Such a change will be detrimental to long term growth, ${ }^{41}$ because the basic research patent owner gets entitled to too large a share of the final invention value. This discourages applied R\&D too much, which more than offsets the increase in basic research. Therefore the demand for skilled labour will fall and so will the skill premium and education.

Interestingly, the stock market value of both monopolists-i.e. both $v_{L}^{0}(t)$ and $v_{L}^{1}(t)$ increase in this scenario. The slight increase in $v_{L}^{0}(t)$ is due to the lower expected obsolescence of the next stage (i.e. lower $n_{A}(t)$ ) combined with the expected increase in the manufacturing profits, which will result from fewer people choosing to educate themselves $^{42}$; these offset the increased industrial obsolescence of the first stage (i.e. higher $\left.n_{B}(t)\right)$.

\footnotetext{
${ }^{41}$ We remind the reader that with these parameters-already used in Fig. 3-the growth-maximizing level of $\bar{\beta}$ is 0.5490 .

42 See Eq. (10).
} 

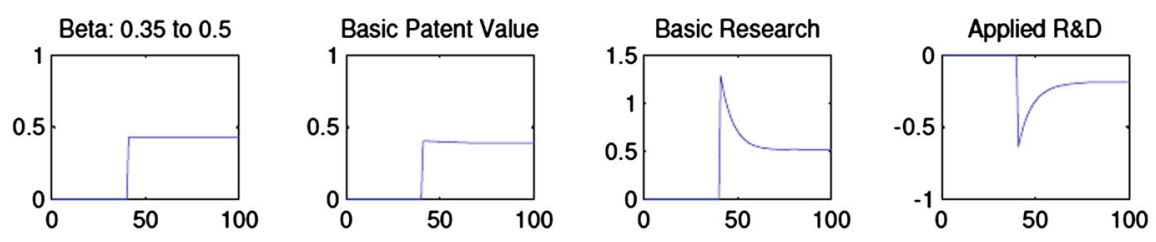

VIO: Monopolist Value AO
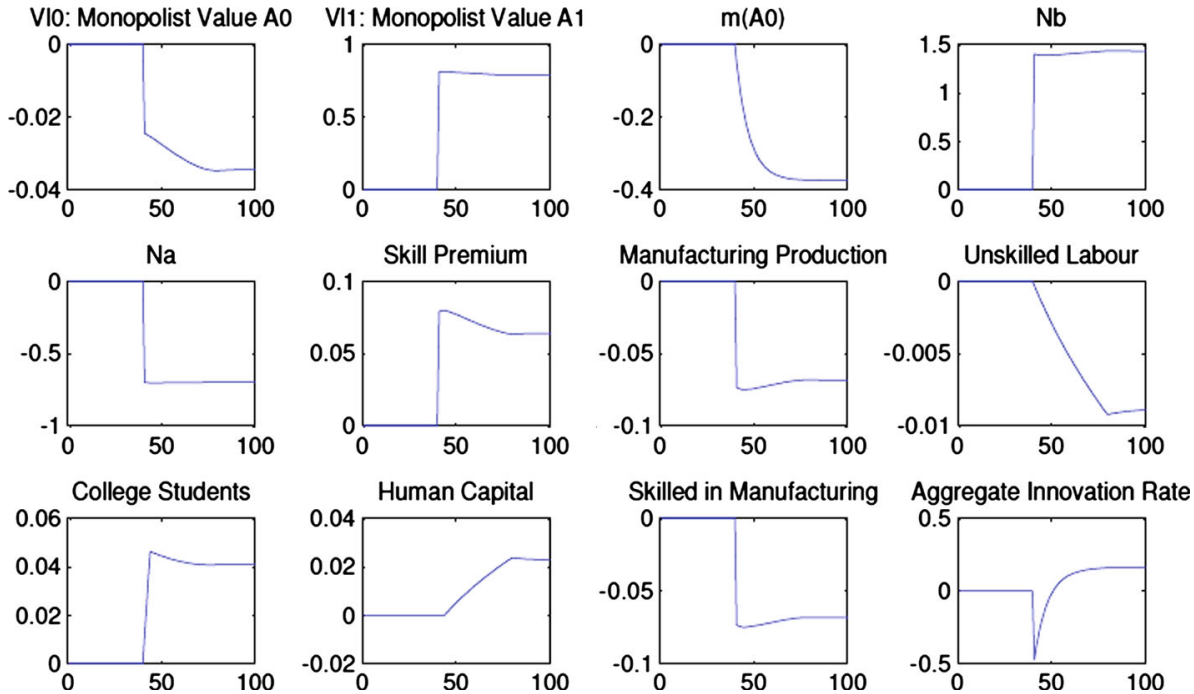

Fig. 8 Growth enhancing transition

We remark that the short term reactions of the skill premium and of manufacturing production could inspire wrong interpretations of the true long term effect of normative changes. In fact, as in the previous discussion, upon impact all stock variables are given, and mainly short term announcement effects prevail. Most notably, the expected gradual increase in $\beta(t)$ fails to penalize current applied R\&D in the order of magnitude as it favours current basic research: basic $R \& D$ will be entitled to a larger share of the results of future applied $R \& D$, not those of current applied $R \& D$. Such temporary win-win situation boosts aggregate $R \& D$

labour and therefore raises the skill premium. However, as $\beta(t)$ sets in, the temporary relief for applied $R \& D$ disappears, and its smaller share of the final product patent penalizes it so much that the ensuing drop in $R \& D$ employment outweighs the increase in basic research employment - the whole effect being corroborated by the gradual increase in $1-m\left(A_{0}(t)\right)$ dragging the skill premium below the initial steady state level and therefore leading towards the new steady state, characterized by less R\&D employment and less innovation.

As a result, our simulations warn policy against relying on empirical evaluations of IPR changes based on relatively short term effects. The short term effects of a harmful tightening, respectively relaxation, of the upstream IPR look misleadingly similar to those of a beneficial bargaining power transfer towards, respectively from, the basic researcher institutions.

The figures shown in this section are considerably robust and representative of the proupstream IPR changes mentioned so far: changing parameters we have observed very similar patterns of short-run and long-run dynamics. ${ }^{43}$

43 The files used to generate them are available to the interested readers. 

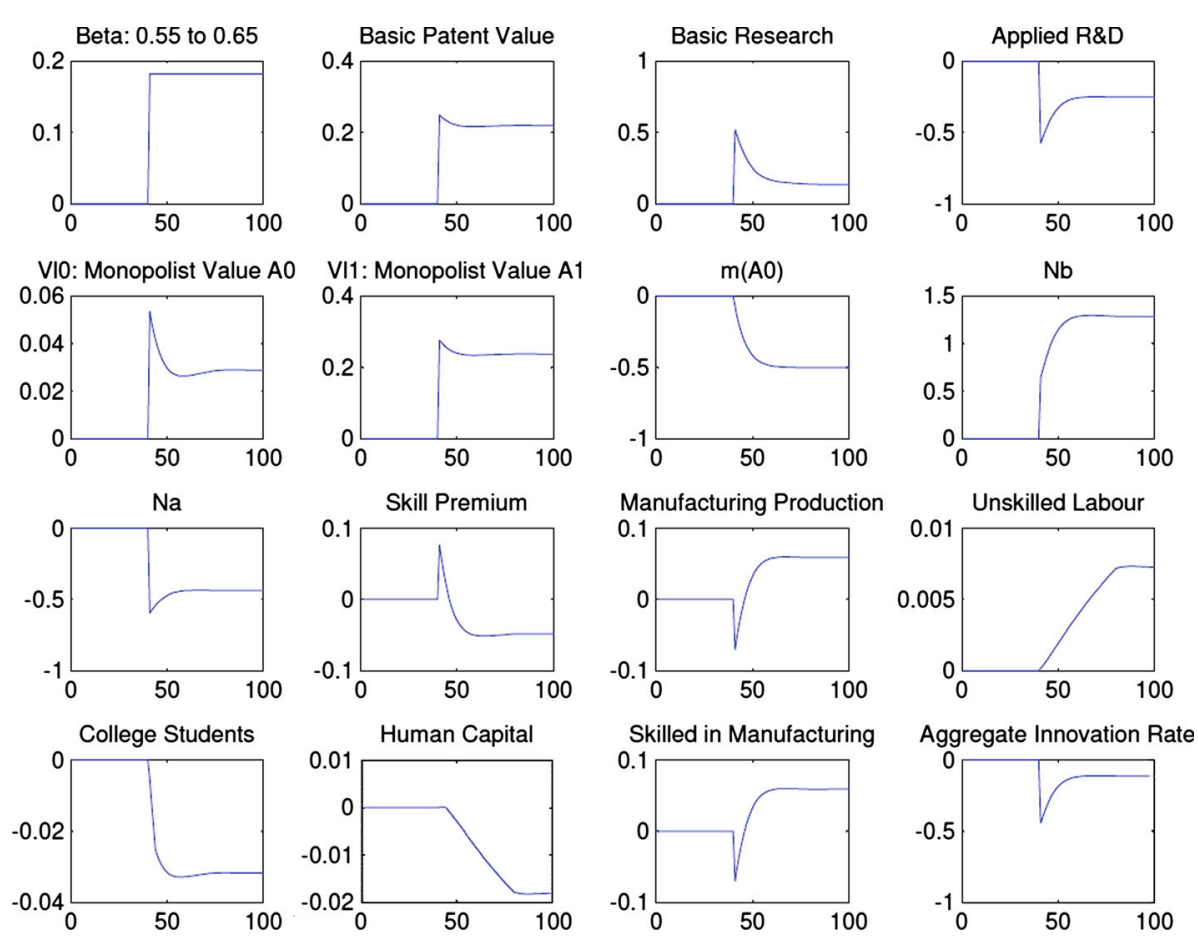

Fig. 9 Growth harming transition

\subsection{An instantaneous change in patent protection}

The previous simulations represented a gradual change in court orientation toward basic research protection, which is certainly characteristic of common law countries. In a civil law country we would expect a more sudden change in $\beta$ to $\bar{\beta}$ : if $\beta$ rises instantaneously to the new level, can the negative short-run effect remain? In this section we show Fig. 8, respectively Fig. 9, which feature identical steady state values as the previous Fig. 6, respectively Fig. 7, except that now at time $41 \beta$ changes discountinuously from 0.35 to 0.50 - in Fig. 8 - and it changes from 0.55 to 0.65 in Fig. 9 . As the reader can see from both figures, in the short run a stronger basic research protection always looks bad for aggregate innovation. We have run several simulations with different parameter values, and always obtained the same qualitative pattern.

\section{Conclusions}

The possibility that innovators may use their patents to block future innovators, and/or prevent them from commercialising their products, is a reason for concern not only among academics. The adoption by the US patent law of a statutory research exemption has been proposed as a definitive solution to this problem. But, by postponing bargaining between innovators it may put the downstream inventor at disadvantage: when is this disadvantage socially beneficial? Can we detect this from the data? This paper has tried to answer these important questions from a dynamic macroeconomic perspective. 
Since the common law system implies gradual transition to new IPR regimes, we have studied the whole transitional dynamics. The most important conclusion is that the transition to a stricter regime does not appear to be monotonic, which shows how assessments based on short term data could be misleading for policy makers. For example, increases in IPR may result in a temporary reduction in economic growth, even if they can be beneficial for long-run growth.

We have also derived an easy to compute approximation of the bargaining power of the upstream researchers, offering an empirical "rule of thumb" that suggests that the year of the celebrated Madey vs. Duke University Federal Circuit's decision, i.e. 2005, marked the apex of the power of basic innovation patent holders, possibly harmful for growth.

Throughout this paper, we have maintained a closed economy framework. It would be very interesting to extend our model to an open economy, whereby potentially offsetting effects may come into play, and contribute to design a more realistic picture, perhaps rendering even more complicated for policy makers to effectively gauge growth-maximizing research policy in a dynamic macroeconomy. For example, the stronger or weaker protection of research tools across contries could direct applied research where the court orientation is less in favour of basic research, which may offset the potentially beneficial effects of higher basic research protection.

An important missing aspect of the model, common in the R\&D-driven growth literature, is the neglect of universities as teaching institutions. They are implicitly present only in their research role, but the extension to the teaching role of universities will certainly be a major topics for future research.

Acknowledgments We thank three anonymous Referees and an Associate Editor for their extremely helpful comments and generous suggestions. We are also grateful to Reiko Aoki, Raouf Boucekkine, Robert Hunt, and seminar participants at the University of Glasgow, Stockholm School of Economics, Hitostubashi University, RIETI centre in Tokyo, University of Durham, University of Mainz, University of Konstanz, University of St. Gallen, SKEMA Business School, University of Zurich, and ETH Zurich for very useful feedback.

\section{Appendix}

Proof of Lemma 1 From Eqs. (22a) and (22c), we have

$$
\frac{\beta}{1-\beta}=\frac{n_{B}^{a}}{\lambda_{0}}\left(\frac{r}{n_{A}}+\frac{\lambda_{1}}{n_{A}^{a}}\right)
$$

which implies that $n_{B}$ is an increasing function of $n_{A}$ and $\beta$, as is $\frac{n_{B}}{n_{A}}$.

Let us rewrite Eq. (11) as $\pi=\frac{1-\gamma}{1-\alpha} l$. Moreover, since $l=\theta_{0}$, Eq. (6) can be rewritten as $w_{H}=\frac{B}{l-\Gamma}$, where $B$ is a constant.

After solving for $v_{L}^{0}$ using Eqs. (22d) and (22e), and in light of the above-mentioned results, we can rewrite Eq. (22c) as:

$$
\frac{B}{l-\Gamma}=\lambda_{1} n_{A}^{-a} \frac{1-\gamma}{1-\alpha} \frac{l(1-\beta)}{r+\lambda_{0} n_{B}^{1-a}}\left[1+\frac{\lambda_{0} n_{B}^{1-a}}{r+\lambda_{1} n_{A}^{1-a}}\right] .
$$

Equations (53) and (54) imply, by the implicit function theorem, that $l$ is a function of $l\left(n_{A}, n_{B}, \beta\right)$ increasing in all its three arguments.

From $l=\theta_{0}$, we can rewrite Eqs. (22a, 22b, 22c, 22d, 22e) as

$$
h(l)=Q\left[\left(1-l^{2}\right)+2 \Gamma(l-1)\right],
$$


where $Q$ is a constant. Notice that $h^{\prime}(l)>0$ in the relevant range, because in equilibrium $l>\Gamma$. Equations (23) and (24) imply that:

$$
\frac{\lambda_{1}+\lambda_{0} \frac{n_{B}}{n_{A}}}{\lambda_{0}+\lambda_{1}\left(\frac{n_{A}}{n_{B}}\right)^{1-a}} n_{A}=h(l)-\frac{\alpha}{1-\alpha} \frac{l(l-\Gamma)}{B} .
$$

Notice that the right hand side of Eq. (55) is decreasing in $l$, and therefore decreasing in $n_{A}, n_{B}$, and $\beta$. Instead, the left hand side of Eq. (55) is increasing in $n_{A}$ and $\beta{ }^{44}$ Therefore, by the implicit function theorem, $n_{A}$ will be an increasing function of $\beta$.

Proof of Proposition 1 From Eqs. (68) and (25) follows that the steady state level of human capital per-capita is an increasing function of the skilled premium $w_{H}$, which we can write as $\bar{h}\left(w_{H}\right)$.

Plugging Eq. (40) into the skilled labour market clearing condition (11) yields:

$$
\left[m\left(A_{0}\right)+\left(1-m\left(A_{0}\right)\right)\left(\frac{\lambda_{1}}{\lambda_{0}} \frac{1-\beta}{\beta}\right)^{\frac{1}{a}}\right] n_{B}=\bar{h}\left(w_{H}\right)-x\left(w_{H}\right) \equiv \Psi\left(w_{H}\right)
$$

with $\Psi^{\prime}\left(w_{H}\right)>0$. Inserting Eqs. (42) into (56) we obtain:

$$
\frac{n_{B}}{\beta\left[1+\left(\frac{\lambda_{0}}{\lambda_{1}}\right)^{\frac{1}{a}}\left(\frac{\beta}{1-\beta}\right)^{\frac{1-a}{a}}\right]}=\bar{h}\left(w_{H}\right)-x\left(w_{H}\right) \equiv \Psi\left(w_{H}\right)
$$

Plugging (39) and Eq. (41) into Eqs. (14a) and (40) we obtain:

$$
\begin{gathered}
w_{H}=\lambda_{0} n_{B}^{-a} \beta v_{L}^{0}=\lambda_{0} n_{B}^{-a} \beta\left[\left(\frac{\lambda_{1}}{\lambda_{0}}\right)^{\frac{1}{a}}\left(\frac{1-\beta}{\beta}\right)^{\frac{1-a}{a}}+1\right] v_{L}^{1} \\
\pi=\lambda_{1} n_{A}^{1-a} v_{L}^{1}=\lambda_{1}\left(\frac{\lambda_{1}}{\lambda_{0}} \frac{1-\beta}{\beta}\right)^{\frac{1-a}{a}} n_{B}^{1-a} v_{L}^{1}
\end{gathered}
$$

From the definition of profits and the steady state mass of unskilled labour, we know that $\pi=\pi\left(w_{H}\right)$, with $\pi^{\prime}\left(w_{H}\right)<0$. Dividing the last two equations side by side implies:

$$
n_{B} \frac{1}{\beta\left[1+\left(\frac{\lambda_{0}}{\lambda_{1}}\right)^{\frac{1}{a}}\left(\frac{\beta}{1-\beta}\right)^{\frac{1-a}{a}}\right]}=\frac{\pi\left(w_{H}\right)}{w_{H}} .
$$

Plugging (59) into (57) gives:

$$
1=\Psi\left(w_{H}\right) \frac{w_{H}}{\pi\left(w_{H}\right)} \equiv \Phi\left(w_{H}\right)
$$

where $\Phi^{\prime}\left(w_{H}\right)>0$. Therefore there exists a unique steady state level of the skill premium obtained as the solution to Eq. (60). It is important to notice that, in this example, the steady state skill premium is independent of $\beta$.

$\overline{44}$ Remember that we have previously proved that $n_{B}$ and $\frac{n_{B}}{n_{A}}$ are increasing functions of $n_{A}$ and $\beta$. 
The steady state innovation rate can be rewritten, after using (59), as:

$$
\begin{aligned}
\lambda_{0} n_{B}^{1-a} m\left(A_{0}\right) & =\frac{\left[\frac{\pi\left(w_{H}\right)}{w_{H}}\right]^{1-a} \beta^{1-a}}{\left[1+\left(\frac{\lambda_{0}}{\lambda_{1}}\right)^{\frac{1}{a}}\left(\frac{\beta}{1-\beta}\right)^{\frac{1-a}{a}}\right]^{a}} \\
& =\frac{\left[\frac{\pi\left(w_{H}\right)}{w_{H}}\right]^{1-a}}{\left[\left(\frac{1}{\lambda_{0}}\right)^{\frac{1}{a}}\left(\frac{1}{\beta}\right)^{\frac{1-a}{a}}+\left(\frac{1}{\lambda_{1}}\right)^{\frac{1}{a}}\left(\frac{1}{1-\beta}\right)^{\frac{1-a}{a}}\right]^{a}}
\end{aligned}
$$

The numerator does not change with $\beta$ as previously proved. The innovation rate is maximized when the denominator is minimized. Hence we need to find a value of $\beta$ such that $\left(\frac{1}{\lambda_{0}}\right)^{\frac{1}{a}}\left(\frac{1}{\beta}\right)^{\frac{1-a}{a}}+\left(\frac{1}{\lambda_{1}}\right)^{\frac{1}{a}}\left(\frac{1}{1-\beta}\right)^{\frac{1-a}{a}}$ is minimized, which implies expression (43).

10.1 Labour supply and education dynamics

\subsubsection{Unskilled labor supply}

As previously shown, individuals born at $t$ with ability $\theta(t) \in\left[0, \theta_{0}(t)\right]$ optimally choose not to educate themselves, thereby immediately joining the unskilled labour force. Hence a fraction $\theta_{0}(t)$ of cohort $t$ remains unskilled their whole life. Summing up over all the older unskilled who are still alive-hence born in the time interval $[t-D, t]$ - we obtain the total stock of unskilled labour as of time $t$ :

$$
L(t)=\int_{t-D}^{t} b N(s) \theta_{0}(s) d s=b \int_{t-D}^{t} e^{g s} \theta_{0}(s) d s
$$

where $b$ is the birth rate, $N(s)$ is the population at time $s$.

To stationarize variables, we divide by current (time $t$ ) population $e^{g s}$, obtaining:

$$
l(t) \equiv \frac{L(t)}{N(t)}=b \int_{t-D}^{t} e^{g(s-t)} \theta_{0}(s) d s .
$$

Its steady state level is:

$$
l=b \frac{1-e^{g(-D)}}{g} \theta_{0}=\theta_{0} .
$$

The change in the stock of the population-adjusted stock of unskilled labour is obtained by derivating $l(t)$ with respect to time:

$$
\dot{l}(t)=b \theta_{0}(t)-b e^{-g D} \theta_{0}(t-D)-g l(t)
$$

As in Boucekkine et al. (2002) and Boucekkine et al. (2007) we obtain a crucial role for delayed differential equations.

\subsubsection{College population}

The individuals born in $t$ with ability $\theta(t) \in\left[\theta_{0}(t), 1\right]$ optimally choose to educate themselves, thereby becoming college students for a training period of duration $\operatorname{Tr}$. Hence sum- 
ming up over all the previous cohorts who are still in college-hence born in the time interval $[t-T r, t]-$ we obtain the total stock of college population as of time $t$ :

$$
\widetilde{C}(t)=b \int_{t-T r}^{t} N(s)\left(1-\theta_{0}(s)\right) d s=b \int_{t-T r}^{t} e^{g s}\left(1-\theta_{0}(s)\right) d s .
$$

In per-capita terms:

$$
\widetilde{c}(t) \equiv \frac{\widetilde{C}(t)}{N(t)}=b \int_{t-T r}^{t} \frac{N(s)}{N(t)}\left(1-\theta_{0}(s)\right) d s=b \int_{t-T r}^{t} e^{g(s-t)}\left(1-\theta_{0}(s)\right) d s .
$$

In a steady state:

$$
\widetilde{c}=b \frac{1-e^{g(-T r)}}{g}\left(1-\theta_{0}\right) .
$$

Taking the derivative of Eq. (64) with respect to time we obtain:

$$
\dot{\tilde{c}}(t)=b\left(1-\theta_{0}(t)\right)-b e^{-g T r}\left(1-\theta_{0}(t-T r)\right)-g \widetilde{c}(t) .
$$

\subsubsection{Human capital}

The stock of skilled workers will coincide with those students who have completed their education and are still alive, born in $[t-D, t-T r]$ :

$$
\widetilde{H}(t)=b \int_{t-D}^{t-T r} N(s)\left(1-\theta_{0}(s)\right) d s=b N(t) \int_{t-D}^{t-T r} e^{g(s-t)}\left(1-\theta_{0}(s)\right) d s
$$

The total workforce (including students) in equilibrium equals total population, hence:

$$
L(t)+\widetilde{H}(t)+\tilde{C}(t)=e^{g t} .
$$

Due to heterogeneous learning abilities, in order to obtain the aggregate skilled labour supply, we need to multiply each skilled worker by the average amount of human capital that she can supply, given by the average skill of her cohort net of dispersion parameter $\Gamma$ :

$$
\int_{\theta_{0}(t)}^{1}(\theta-\Gamma) \frac{1}{1-\theta_{0}(t)} d \theta=\frac{1+\theta_{0}(t)-2 \Gamma}{2} .
$$

Therefore the aggregate amount of skilled labour in efficiency units (skilled labor supply) is:

$$
H(t)=b N(t) \int_{t-D}^{t-T r} \frac{e^{g(s-t)}\left(1-\theta_{0}(s)\right)\left(1+\theta_{0}(s)-2 \Gamma\right)}{2} d s
$$

Dividing by time $t$ population, we can express per-capita human capital as:

$$
h(t) \equiv \frac{H(t)}{N(t)}=\frac{b}{2} \int_{t-D}^{t-T r} e^{g(s-t)}\left(1-\theta_{0}(s)\right)\left(1+\theta_{0}(s)-2 \Gamma\right) d s .
$$


The steady state value is:

$$
h=b \frac{\left[e^{g(-T r)}-e^{g(-D)}\right]\left(1-\theta_{0}\right)\left(1+\theta_{0}-2 \Gamma\right)}{2 g}
$$

The dynamics of human capital can be studied by derivating both sides of Eq. (67) with respect to time:

$$
\begin{aligned}
\dot{h}(t)= & -g h(t)+\frac{b}{2} e^{-g T r}\left(1-\theta_{0}(t-T r)\right)\left(1+\theta_{0}(t-T r)-2 \Gamma\right)- \\
& +\frac{b}{2} e^{-g D}\left(1-\theta_{0}(t-D)\right)\left(1+\theta_{0}(t-D)-2 \Gamma\right) .
\end{aligned}
$$

10.2 Transitional properties of educational choice

The study of the transition dynamics of this model is complicated by the skilled/unskilled labour dynamics and by the endogenous education choice under perfect foresight. Key to the solution is the transformation of the integral equation for the ability threshold level for education into a set of differential equations.

Defining the present value of the unskilled wage incomes as $W_{U}(t)=\int_{t}^{t+D} e^{-\int_{t}^{s} i(\tau) d \tau} d s$ and the present value of the skilled wage income as $W_{S}(t)=\int_{t+T r}^{t+D} e^{-\int_{t}^{s} i(\tau) d \tau} w_{H}(s) d s$, we know from (24) that

$$
\theta_{0}(t)=\Gamma+\frac{W_{U}(t)}{W_{S}(t)}
$$

Defining

$$
\begin{aligned}
& R_{1}(t)=e^{-\int_{t}^{t+D} i(\tau) d \tau}, \text { and } \\
& R_{2}(t)=e^{-\int_{t}^{t+T r} i(\tau) d \tau}
\end{aligned}
$$

we can write:

$$
\begin{aligned}
& \dot{W}_{U}(t)=R_{1}(t)-1+i(t) W_{U}(t) \\
& \dot{W}_{S}(t)=R_{1}(t) w_{H}(t+D)-R_{2}(t) w_{H}(t+T r)+i(t) W_{S}(t) .
\end{aligned}
$$

Differentiating Eqs. (71)-(72) with respect to time we obtain:

$$
\begin{aligned}
& \dot{R}_{1}(t)=R_{1}(t)(i(t)-i(t+D)), \text { and } \\
& \dot{R}_{2}(t)=R_{2}(t)(i(t)-i(t+T r)) .
\end{aligned}
$$

These equations allow us to cast our model in a framework that can be studied in terms of delayed differential equations.

10.3 Expenditure and manufacturing dynamics

From Eq. (10) follows:

$$
\frac{\gamma-1}{\gamma} e(t)=(\gamma-1) \frac{1}{1-\alpha} l(t) .
$$

Log-differentiating with respect to time, using Euler equation (3) and the unskilled law of motion (63) yield:

$$
i(t)-(\rho+g)=\frac{\dot{e}(t)}{e(t)}=\frac{i(t)}{l(t)}=\frac{b \theta_{0}(t)-b e^{-g D} \theta_{0}(t-D)}{l(t)}-g
$$


that-since $r(t)=i(t)-g$-can be rewritten as

$$
r(t)-\rho=\frac{b \theta_{0}(t)-b e^{-g D} \theta_{0}(t-D)}{l(t)}-g,
$$

In the steady state: $r(t)=\rho$.

\section{References}

Acemoglu, D. (1998). Why do new technologies complement skills? Directed technical change and wage inequality. Quarterly Journal of Economics, 113(4), 1055-1058.

Acemoglu, D. (2002). Directed technical change. The Review of Economic Studies, 69(4), 781-809.

Akcigit, U., Hanley, D., \& Serrano-Velarde, N. (2012). Back to basics: Basic research spillovers, innovation policy and growth. Manuscript, University of Pennsylvania.

Aghion, P., \& Howitt, P. (1992). A model of growth through creative destruction. Econometrica, 60(2), 323351.

Aghion, P., \& Howitt, P. (1996). Research and development in the growth process. Journal of Economic Growth, 1, 13-25.

Aghion, P., \& Tirole, J. (1994a). Opening the black box of innovation. European Economic Review, 38(3-4), 701-710.

Aghion, P., \& Tirole, J. (1994b). The management of innovation. Quarterly Journal of Economics, 109(4), 1185-1209.

Berman, E., Bound, J., \& Griliches, Z. (1994). Changes in the demand for skilled labor within U.S. manufacturing: Evidence from the annual survey of manufacturers. The Quarterly Journal of Economics, 109(2), 367-397.

Bessen, J., \& Maskin, E. (2009). Sequential innovation, patents, and imitation. RAND Journal of Economics, 40(4), 611-635.

Boucekkine, R., de la Croix, D., \& Licandro, O. (2002). Vintage human capital, demographic trends, and endogenous growth. Journal of Economic Theory, 104(2), 340-375.

Boucekkine, R., de la Croix, D., \& Peeters, D. (2007). Early literacy achievements, population density, and the transition to modern growth. Journal of the European Economic Association, 5(1), 183-226.

Carlino, C., \& Hunt, R. M. (2001). Knowledge spillovers and the new economy of cities. Working Paper, FED of Philadelphia, pp. 1-14.

Chu, A. (2008). Special interest politics and intellectual property rights: An economic analysis of strengthening patent protection in the pharmaceutical Industry. Economics and Politics, 20(2), 185-215.

Chu, A. (2009). Effects of blocking patents on R\&D: A quantitative DGE analysis. Journal of Economic Growth, 14(1), 55-78.

Chu, A. (2010). Effects of patent policy on income and consumption inequality in a R\&D growth model. Southern Economic Journal, 77(2), 336-350.

Chu, A. (2010). The welfare cost of one-size-fits-all patent protection. Journal of Economic Dynamics and Control, 35(6), 876-890.

Chu, A., Cozzi, G., \& Galli, S. (2012). Does intellectual monopoly stimulate or stifle innovation? European Economic Review, 56(4), 727-746.

Cozzi, G. (2001). Inventing or spying? Implications for growth. Journal of Economic Growth, 6(1), 55-77.

Cozzi, G. (2007). The Arrow effect under competitive R\&D. The B.E. Journal of Macroeconomics, 7(1), 1-20.

Cozzi, G., \& Galli, S. (2009). Science-based R\&D in Schumpeterian growth. Scottish Journal of Political Economy, 56-4(September), 474-491.

Dinopoulos, E., \& Segerstrom, P. S. (1999). A Schumpeterian model of protection and relative wages. American Economic Review, 89(3), 450-472.

Dinopoulos, E., \& Thompson, P. S. (1998). Schumpeterian growth without scale effects. Journal of Economic Growth, 3, 313-335.

Dinopoulos, E., \& Thompson, P. S. (1999). Scale effects in Neo-Schumpeterian models of economic growth. Journal of Evolutionary Economics, 9(2), 157-186.

Eicher, T., \& García-Peñalosa, C. (2008). Endogenous strength of intellectual property rights: Implications for economic development and growth. European Economic Review, 52(2), 237-258.

Ellison, M., Keller, G., Roberts, K., \& Stevens, M. (2013). Unemployment and market size. The Economic Journal. doi:10.1111/ecoj.12043. 
Fon, V., \& Parisi, F. (2006). Judicial precedents in civil law systems: A dynamic analysis. International Review of Law and Economics, 26, 519-535.

Furukawa, Y. (2007). The protection of intellectual property rights and endogenous growth: Is stronger always better? Journal of Economic Dynamics and Control, 31(11), 3644-3670.

Galasso, A., \& Schankerman, M. (2013). Patents and cumulative innovation: Causal evidence from the courts. CEPR Discussion Paper 9458.

Gallini, N. (2002). The economics of patents: Lessons from recent U.S. Patent reform. Journal of Economic Perspectives, 2, 131-154.

Galor, O., \& Moav, O. (2000). Ability-biased technological transition, wage inequality, and economic growth. The Quarterly Journal of Economics, 115(2), 469-497.

Gennaioli, N., \& Shleifer, A. (2007a). The evolution of common law. Journal of Political Economy, 115, 43-68.

Gennaioli, N., \& Shleifer, A. (2007b). Overruling and the instability of law. Journal of Comparative Economics, 35(2), 309-328.

Gersbach, H., Schneider, M., \& Schneller, O. (2010). Optimal mix of applied and basic research, distance to frontier, and openness. CEPR Discussion Papers 7795. Discussion Papers, C.E.P.R.

Gersbach, H., \& Schneider, M. (2012). Basic research, openness, and convergence. Journal of Economic Growth, 18(1), 33-68.

Green, J., \& Scotchmer, S. (1995). On the division of profit in sequential innovations. The Rand Journal of Economics, 26, 20-33.

Grossman, G. M., \& Helpman, E. (1991a). Quality ladders in the theory of growth. Review of Economic Studies, 58, 43-61.

Grossman, G. M., \& Helpman, E. (1991b). Innovation and growth in the global economy. Cambridge, MA: MIT Press.

Grossman, G. M., \& Shapiro, C. (1987). Dynamic R\&D competition. The Economic Journal, 97, 372-387.

Ha, J., \& Howitt, P. (2007). Accounting for trends in productivity and R\&D: A Schumpeterian critique of semi-endogenous growth theory. Journal of Money, Credit, and Banking, 39(4), 74-733.

Hall, H. B. (2009). Business and financial method patents: Innovation and policy. Scottish Journal of Political Economy, 56(s1), 443-473.

Heller, M. A., \& Eisenberg, R. S. (1998). Can patents deter innovation? The anticommons in biomedical research. Science, 280(5364), 698-701.

Hosios, A. J. (1990). On the efficiency of matching and related models of search and unemployment. Review of Economic Studies, 57, 279-98.

Howitt, P. (1999). Steady endogenous growth with population and R\&D inputs growing. Journal of Political Economy, 107(4), 715-730.

Hunt, R. M. (2001). You can patent that? Are patents on computer programs and business methods good for the new economy? Federal of Philadelphia Business Review, Q1, 5-15.

Jones, C. (2005). Growth in a world of ideas. In P. Aghion \& S. Durlauf (Eds.), Handbook of economic growth. Amsterdam: North-Holland.

Jones, C., \& Williams, J. (1998). Measuring the social return to R\&D. Quarterly Journal of Economics, 113, 1119-1135.

Jones, C., \& Williams, J. (2000). Too much of a good thing? The economics of investment in R\&D. Journal of Economic Growth, 5(1), 65-85.

Kiley, M. (1999). The supply of skilled labour and skill-biased technological progress. Economic Journal, 109(458), 708-724.

Madsen, J. B. (2008). Semi-endogenous versus Schumpeterian growth models: Testing the knowledge production function using international data. Journal of Economic Growth, 3(1), 1-26.

Martins, J., \& Scarpetta, S. (1996). Markup pricing. Market structure and the business cycle. OECD Economic Studies, 27, 71-105.

Maurer, S. M., \& Scotchmer, S. (2004). A primer for nonlawyers on intellectual property. In S. Scotchmer (Ed.), Innovation and incentives. Cambridge, MA: MIT Press.

Mueller, J. M. (2001). No 'Dilettante Affair"': Rethinking the experimental use exception to patent infringement for biomedical research tools. 76 Wash. L. Rev., 1, 22-27.

Mueller, J. M. (2004). The evanescent experimental use exemption from United States patent infringement liability: Implications for university and nonprofit research and development. Baylor Law Review, $56,917$.

National Science Foundation. (2013). National Patterns of R\&D Resources: 2010-2011 Data Update.

O'Donoghue, T., \& Zweimüller, J. (2004). Patents in a model of endogenous growth. Journal of Economic Growth, 9(1), 81-123.

Peretto, P. (1998). Technological change and population growth. Journal of Economic Growth, 3, $283-311$. 
Peretto, P. (1999). Cost reduction, entry, and the interdependence of market structure and economic growth. Journal of Monetary Economics, 43(1), 95-173.

Roeger, W. (1995). Can imperfect competition explain the difference between primal and dual productivity measures? Estimates for US manufacturing. Journal of Political Economy, 103(2), 316-330.

Scotchmer, S. (2004). Innovation and incentives. Cambridge, MA: MIT Press.

Segerstrom, P. (1998). Endogenous growth without scale effects. American Economic Review, 88(5), 12901310.

Segerstrom, P., Anant, T., \& Dinopoulos, E. (1990). A Schumpeterian model of the product life cycle. American Economic Review, 80(5), 1077-1091.

Smulders, S., \& van de Klundert, T. (1995). Imperfect competition, concentration and growth with firm-specific R \& D. European Economic Review, 39(1), 139-160.

Spinesi, L. (2007). IPR for public and private innovations, and growth. Discussion Paper 2007-15, Catholic University of, Louvain-la-Neuve.

Spinesi, L. (2012). Heterogeneous academic-industry knowledge linkage, heterogeneous IPR, and growth. Journal of Public Economic Theory, 14(1), 67-98.

Young, A. (1998). Growth without scale effects. Journal of Political Economy, 106, 41-63. 